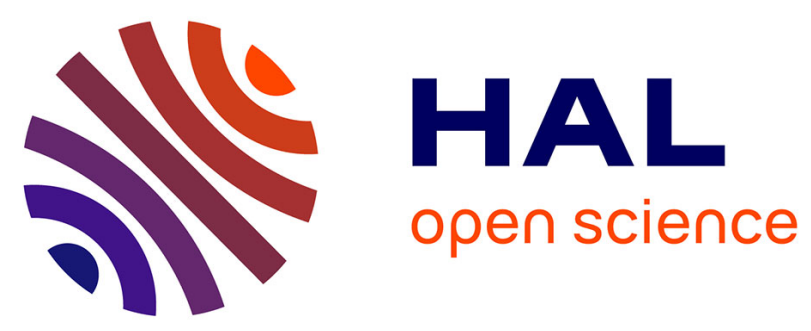

\title{
Validation of AERONET estimates of atmospheric solar fluxes and aerosol radiative forcing by ground-based broadband measurements
}

\author{
O. García, A. Díaz, F. Expósito, J. Díaz, O. Dubovik, P. Dubuisson, \\ Jean-Claude Roger, T. Eck, A. Sinyuk, Y. Derimian, et al.
}

\section{To cite this version:}

O. García, A. Díaz, F. Expósito, J. Díaz, O. Dubovik, et al.. Validation of AERONET estimates of atmospheric solar fluxes and aerosol radiative forcing by ground-based broadband measurements. Journal of Geophysical Research, 2008, 113 (D21), 10.1029/2008JD010211 . hal-03471353

\author{
HAL Id: hal-03471353 \\ https://hal.uca.fr/hal-03471353
}

Submitted on 31 Dec 2021

HAL is a multi-disciplinary open access archive for the deposit and dissemination of scientific research documents, whether they are published or not. The documents may come from teaching and research institutions in France or abroad, or from public or private research centers.
L'archive ouverte pluridisciplinaire HAL, est destinée au dépôt et à la diffusion de documents scientifiques de niveau recherche, publiés ou non, émanant des établissements d'enseignement et de recherche français ou étrangers, des laboratoires publics ou privés. 


\title{
Validation of AERONET estimates of atmospheric solar fluxes and aerosol radiative forcing by ground-based broadband measurements
}

\author{
O. E. García, ${ }^{1}$ A. M. Díaz, ${ }^{1}$ F. J. Expósito, ${ }^{1}$ J. P. Díaz, ${ }^{1}$ O. Dubovik,${ }^{2}$ P. Dubuisson, ${ }^{2}$ \\ J.-C. Roger, ${ }^{3}$ T. F. Eck, ${ }^{4,5}$ A. Sinyuk, ${ }^{4,6}$ Y. Derimian, ${ }^{2}$ E. G. Dutton, ${ }^{7}$ J. S. Schafer, ${ }^{6,8}$ \\ B. N. Holben, ${ }^{8}$ and C. A. García ${ }^{9}$
}

Received 2 April 2008; revised 22 July 2008; accepted 25 August 2008; published 11 November 2008.

[1] The AErosol RObotic NETwork (AERONET) estimates of instantaneous solar broadband fluxes $(\mathrm{F})$ at surface have been validated through comparison with ground-based measurements of broadband fluxes at Mauna Loa Observatory (MLO) and by the Baseline Surface Radiation (BSRN) and the Solar Radiation Networks (SolRad-Net) during the period 1999-2005 and 1999-2006, respectively. The uncertainties in the calculated aerosol radiative forcing $(\Delta \mathrm{F})$ and radiative forcing efficiency $\left(\Delta \mathrm{F}^{\mathrm{eff}}\right)$ at the bottom of the atmosphere were also assessed. The stations have been selected attempting to cover different aerosols influences and hence radiative properties: urban-industrial, biomass burning, mineral dust, background continental, maritime aerosols and free troposphere. The AERONET solar downward fluxes at surface agree with ground-based measurements in all situations, with a correlation higher than $99 \%$ whereas the relation of observed to modeled fluxes ranges from 0.98 to 1.02. Globally an overestimation of $9 \pm 12 \mathrm{Wm}^{-2}$ of solar measurements was found, whereas for MLO (clear atmosphere) the differences decrease noticeably up to $2 \pm 10 \mathrm{Wm}^{-2}$. The highest dispersion between AERONET estimates and measurements was observed in locations dominated by mineral dust and mixed aerosols types. In these locations, the $\mathrm{F}$ and $\Delta \mathrm{F}$ uncertainties have shown a modest increase of the differences for high aerosol load, contrary to $\Delta \mathrm{F}^{\text {eff }}$ which are strongly affected by low aerosol load. Overall the discrepancies clustered within $9 \pm 12 \mathrm{Wm}^{-2}$ for $\Delta \mathrm{F}$ and $28 \pm 30 \mathrm{Wm}^{-2}$ per unit of aerosol optical depth, $\tau$, at $0.55 \mu \mathrm{m}$ for $\Delta \mathrm{F}^{\text {eff }}$, where the latter is given for $\tau(0.44 \mu \mathrm{m}) \geq 0.4$. The error distributions have not shown any significant tendency with other aerosol radiative properties as well as size and shape particles.

Citation: García, O. E., et al. (2008), Validation of AERONET estimates of atmospheric solar fluxes and aerosol radiative forcing by ground-based broadband measurements, J. Geophys. Res., 113, D21207, doi:10.1029/2008JD010211.

\section{Introduction}

[2] The Earth's climate is strongly influenced by the radiation budget of the Earth-Atmosphere system, i.e., by

\footnotetext{
${ }^{1}$ Grupo de Observación de la Tierra y la Atmósfera, Universidad de La Laguna, La Laguna, Tenerife, Spain.

${ }^{2}$ Laboratoire d'Optique Amosphérique, Université des Sciences et Technologies de Lille, Villeneuve d'Ascq, France.

${ }^{3}$ Laboratoire de Météorologie Physique, Université Blaise Pascal, Clermont-Ferrand, France.

${ }^{4}$ Laboratory for Terrestrial Physics, NASA Goddard Spaceflight Center, Greenbelt, Maryland, USA.

${ }^{5}$ Goddard Earth Sciences and Technology Center, University of Maryland-Baltimore County, Baltimore, Maryland, USA.

${ }^{6}$ Science Systems and Applications, Inc., Lanham, Maryland, USA.

${ }^{7}$ NOAA Climate Monitoring and Diagnostics Laboratory, Boulder, Colorado, USA.

${ }^{8}$ Biospheric Sciences Branch, NASA Goddard Space Flight Center, Greenbelt, Maryland, USA.

${ }^{9}$ Departamento de Estadística e Investigación Operativa, Universidad de La Laguna, La Laguna, Tenerife, Spain.
}

Copyright 2008 by the American Geophysical Union. 0148-0227/08/2008JD010211 the absorbing and scattering processes that affect both to incoming solar radiation and outgoing terrestrial energy. Any small perturbation on this global energy balance can cause a profound change in climate [Ohmura et al., 1998; Intergovernmental Panel on Climate Change (IPCC), 2001]. In this context, the influence of atmospheric aerosols is one of the most important factors of this climate system and, despite of our present understanding have increased in last years, they still are one of the largest unknown variables. In fact, recently, the total anthropogenic radiative effect on global scale was estimated to be $+1.6(-1.0$ to $+0.8) \mathrm{Wm}^{-2}$, of which $-0.5( \pm 0.4) \mathrm{Wm}^{-2}$ are associated to the direct radiative forcing of the atmospheric aerosols whereas $-0.7(-1.1$ to +0.4$) \mathrm{Wm}^{-2}$ are due to the indirect effect of these components on cloud microphysics, modifying the cloud albedo [IPCC, 2007]. However, the uncertainty remains large.

[3] According to the recent report of IPCC [2007], the direct radiative forcing of the individual aerosol species is less certain than the total direct radiative forcing by all aerosols, for which long-term monitoring of different 
aerosol types is necessary to improve the knowledge of changes in radiative forcing and climate parameters. In this sense, the AErosol RObotic NETwork (AERONET) is one of the most useful tools nowadays [Holben et al., 1998], which provides enough information to establish globally a ground-based aerosol climatology [Holben et al., 2001; Smirnov et al., 2002; Dubovik et al., 2002a; Kaskaoutis et al., 2007]. An extended set of physical and optical aerosol properties, averaged in the atmospheric column, such as detailed particle size distribution, complex refractive index, single scattering albedo, and particle shape information [Dubovik et al., 2002a, 2006] given at more than 180 worldwide locations have enabled verification of global aerosol models [e.g., Sato et al., 2003; Zhou et al., 2005] and satellite retrievals [e.g., Remer et al., 2005; García et al., 2008]. In addition, at present, AERONET provides a set of estimates of direct solar effects caused by atmospheric aerosols (spectral and broadband fluxes, aerosol radiative forcing and aerosol radiative forcing efficiency), which helps to decrease the uncertainty range managed until now. These instantaneous estimates are derived using aerosol properties retrieved from sets of direct Sun and diffuse sky radiances measurements in solar almucantar (details are given by O. Dubovik et al., Enhanced retrieval of aerosol properties from atmospheric radiation measured by AERONET Sun/sky-radiometers, manuscript in preparation, 2008, also see AERONET web site: http://aeronet.gsfc.nasa.gov).

[4] In order to use these radiative magnitudes with total certainty it is necessary to establish a level of accuracy for these values as well as to analyze the possible error sources. The accuracy of the AERONET retrievals Version 1.0, complex refractive index and size distribution, has been widely described by Dubovik et al. [2000]. Modifications as the use of a spheroid mixture as a generalized aerosol model [Dubovik et al., 2006] and refined surface properties [Sinyuk et al., 2007; Eck et al., 2008], introduced in Version 2.0, are expected to improve the accuracy of aerosol retrievals in new Version 2.0. Nevertheless derived products as the broadband fluxes, aerosol radiative forcing and forcing efficiency have not been yet validated experimentally. Therefore the purpose of the present study is to compare the AERONET estimates of broadband radiative properties with co-incident ground-based measurements from solar databases. The comparisons are focused on validation of both the radiative forcing and forcing efficiency for different aerosol types and for variable loading conditions.

[5] The paper is divided in several parts. Sections 2 and 3 provide a detailed description of the database and stations used. Section 4 explains the methodology applied to validate the AERONET radiative magnitudes. Finally, section 5 presents the results of the validation and the sensitivity tests of AERONET errors under different aerosol regimes.

\section{Instrumentation and Data Sets}

[6] The solar radiation measurements needed to validate the AERONET solar broadband fluxes, and hence aerosol radiative forcing and forcing efficiency, were taken from three sources: a subsample of the available stations from the Baseline Surface Radiation Network (BSRN, http:// bsrn.ethz.ch/), the Solar Radiation Network (SolRad-Net, http://solrad-net.gsfc.nasa.gov/) and the NOAA Solar and
Infrared Radiation program from Mauna Loa Observatory (MLO, http://www.mlo.noaa.gov/). These radiation measurements have been used widely to validate both global climate models and satellite algorithms, as well as, to register radiation trends at surface level due to their high level of accuracy [e.g., Ohmura et al., 1998; Dutton and Bodhaine, 2001; Hatzianastassiou et al., 2005].

\subsection{Solar Databases: SolRad-Net, BSRN and MLO}

[7] Solar Radiation Network (SolRad-Net) is an established network of ground-based sensors that provides high-frequency solar flux measurements in quasi-real time, associated to AERONET. At the beginning, this network selected sites frequently affected by intervals of biomass burning, such as Amazonia and Sub-Saharan Africa, but more recently the aerosol monitoring has been widened. This database covers records of different solar ranges as photosynthetically active radiation or ultraviolet plus visible irradiance, but only the shortwave solar spectrum $(0.305-2.8 \mu \mathrm{m})$ was used in this work. Kipp and Zonen CM-21 pyranometers are the reference instrument used to measure the total solar flux. Because of the high stability of this type of instrument, they have been calibrated using the manufacturer supplied calibration factors, which provide a $2 \%$ of accuracy, with calibration shift less than $1 \%$ per year. The data used correspond to the highest quality level 2.0, which have been cloud screened, cleared of any operational problems and also they include a pre-and post-calibration determined from Kipp and Zonen (http://solrad-net.gsfc. nasa.gov/). The instantaneous irradiance is recorded at 1 or 2-minute intervals, depending on the site settings.

[8] BSRN is a project of the World Climate Research Program (WCRP) and the Global Energy and Water Experiment (GEWEX) and it was recently (early 2004) designated as the global baseline network for surface radiation for the Global Climate Observing Systems (GCOS). The worldwide BSRN stations are distributed in order to cover major climate zones, where solar and atmospheric radiation is measured with instruments of the highest available accuracy and with high temporal resolution (one to three minutes). In this sense the BSRN measurements follow specific calibration procedures, checked by WCRP, being the target uncertainties which determine the selected instrumentation of the network. In the case of global radiation, the BSRN stations use two methodologies to measure the solar irradiance: single pyranometer and the combined sum of the two components of solar radiation (direct and diffuse). Although the latter method minimizes the uncertainties on solar radiation measurements decreasing the errors due to the nonideal angular response of the single pyranometers [Ohmura et al., 1998; Michalsky et al., 1999], the observed ones by typical pyranometers were used in order to unify the ground-based measurements managed in the comparisons. Kipp and Zonen CM-21 and Eppley PSP pyranometers were the selected instruments, being the combined errors due to calibration, angular response, etc., usually less than $3 \%-5 \%$ of the instantaneous instrument signal [Dutton et al., 2001, and references herein]. The spectral range measured in each station goes from 0.285 or 0.305 to $2.8 \mu \mathrm{m}$.

[9] Mauna Loa Observatory is part of the National Oceanic and Atmospheric Administration (NOAA), Earth 
System Research Laboratory (ESRL) and the Global Monitoring Division (GMD). Measurements of solar radiation have been made at MLO since 1978, recording both direct and diffuse solar irradiance. Following the BSRN recommendation, the total solar irradiance is derived from the sum of these two components, which minimizes the uncertainties [Ohmura et al., 1998], and the accuracy of the component-sum method would be combination of its own uncertainties. For the direct component the expected accuracy is within about $0.5 \%$ [Dutton and Bodhaine, 2001], whereas the diffuse measurements are correct about 3-4 $\mathrm{Wm}^{-2}$ [Kato et al., 1999]. The broadband solar radiation is given from 0.285 to $2.8 \mu \mathrm{m}$, with a temporal resolution of one minute.

[10] In order to avoid the cloud contamination on instantaneous surface measurements, the solar database was screened following an empirical clear-sky detection filter [Schafer et al., 2002b; Xia et al., 2007]. This scheme is based on the relation of the solar global irradiance and cosine of solar zenith angle under clear sky conditions, where the measured irradiance can be simulated by a power law function [Long and Ackerman, 2000]. In a first step, this fit is evaluated in a running window of the 2 hour centered on each instantaneous solar measurement, ruling out those observations with an absolute relative deviation greater than $20 \%$ regarding the simulated values. Thus situations with high variability due to scattered and broken cloud cover are removed, but a slight enhancement by peripheral clouds can remain. To exclude that, the variability of the measured irradiance normalized by simulated values is checked over a 30 minutes window, eliminating the observation by cloud presence if the standard deviation is greater than 0.02 [Xia et al., 2007]. Nevertheless in this second step, we have observed that a considerable number of clear sky observations were also filtered, especially for observations at desert stations. In most of these cases, the values higher than this limit (0.02) might be due to the aerosol load variability or natural evolution of the daily solar irradiance. In such conditions, the variability is tested reevaluating the fit model (power law) to the new temporal window ( \pm 15 minutes). In order to validate the AERONET radiative magnitudes, the filtered clear sky solar measurements are collocated temporally with the cloud-screened AERONET retrievals as is described in detail in section 4, which will eliminate those observations acquired during uniform cloud conditions.

\subsection{AERONET Database}

[11] AERONET is one of the most useful global networks of atmospheric aerosols monitoring (http://aeronet.gsfc.nasa. gov), which collects near real time observations of spectral and columnar integrated aerosol optical properties. With this aim, automatic sun and sky scanning spectral radiometers manufactured by CIMEL Electonique are distributed on worldwide locations [Holben et al., 1998, 2001]. Depending on the model of CIMEL radiometers, the direct Sun measurements may be taken on all or some of the following channels: $0.34,0.38,0.44,0.50,0.67,0.87,0.94,1.02$, and $1.64 \mu \mathrm{m}$ (nominal wavelengths), retrieving aerosol optical depth at all these wavelengths except at $0.94 \mu \mathrm{m}$, which is the channel used to estimate total precipitable water content. In addition to the direct solar radiance measurements, that are made with a field of view of 1.2 degrees, these instruments measure the sky radiance in four spectral bands $(0.44,0.67$, 0.87 , and $1.02 \mu \mathrm{m}$ ) along both the solar principal plane and the solar almucantar.

[12] Solar aureole/sky radiance together with Sun measurements are used to retrieve aerosol volume size distributions (from 0.05 to $15 \mu \mathrm{m}$ ), spectral complex refractive index ( $n$ and $k$ ) and single scattering albedo $(\omega)$, following a flexible inversion algorithm developed by Dubovik and King [2000] (Version 1.0 inversion products), which uses models of homogeneous spheres and randomly oriented spheroids [Dubovik et al., 2002b]. Recently a new version of this inversion algorithm, Version 2.0, has been developed, where the most significant modification is the use of a spheroid mixture as a generalized aerosol model (representing spherical, nonspherical, and mixed aerosols) [Dubovik et al., 2006], replacing the spherical and spheroid models used separately up to now. In this vein, Version 2.0 provides a parameterization of the degree of non-sphericity, as well as the same set of retrieved aerosol parameters given in Version 1.0 (size distributions and complex refractive index). Another important addition in the AERONET inversion products Version 2.0 is that a set of radiative properties are given at any AERONET station: spectral and broadband fluxes, besides aerosol radiative forcing and aerosol radiative forcing efficiency, which allow to study the radiative effects under different aerosols. The validation of these parameters, calculated from the retrieved aerosol properties [Dubovik et al., 2008, in preparation] and described in detail in section 4, is the main goal of the present study.

[13] Level of accuracy in the CIMEL measurements is a critical issue in the inversion process, since the retrieval algorithm is set to fit the data to the level of AERONET measurement uncertainty, i.e., the nominal error in $\tau$ is assumed $0.015^{*} \operatorname{cosine}($ solar zenith angle) whereas for sky radiance measurements the error is $\pm 5 \%$. These values are determined by the calibration conditions. For the direct measurements, calibration of field instruments is performed by a transfer of calibration from reference CIMELs, which are calibrated by the Langley plot technique at Mauna Loa Observatory (Hawaii). Typically, the total uncertainty in spectral aerosol optical depth for a field instruments ranges from 0.01 to 0.02 under cloud-free conditions for air mass equal one [Eck et al., 1999], with the highest errors (0.02) associated to the ultraviolet wavelengths. For the sky radiance measurements, calibration is performed by comparing to a reference integrating sphere with an accuracy of $\pm 5 \%$ or better at the NASA Goddard Calibration Facility [Holben et al., 1998]. With respect to the long-term stability of the calibration coefficients, the optical interference filters are the main limiting factors. On average, a decrease from 0 to $\sim 5 \%$ per year is expected, depending largely on material deposition on the optics.

\section{Sites Description}

[14] From the BSRN and SolRad-Net networks the ground-based stations have been selected attending to the aerosol influences besides the spatial and temporal collocation with the AERONET stations (Figure 1). Thus, the validation of AERONET solar fluxes has been carried out under five key aerosol types with significant differences in optical properties and also different influences on solar 


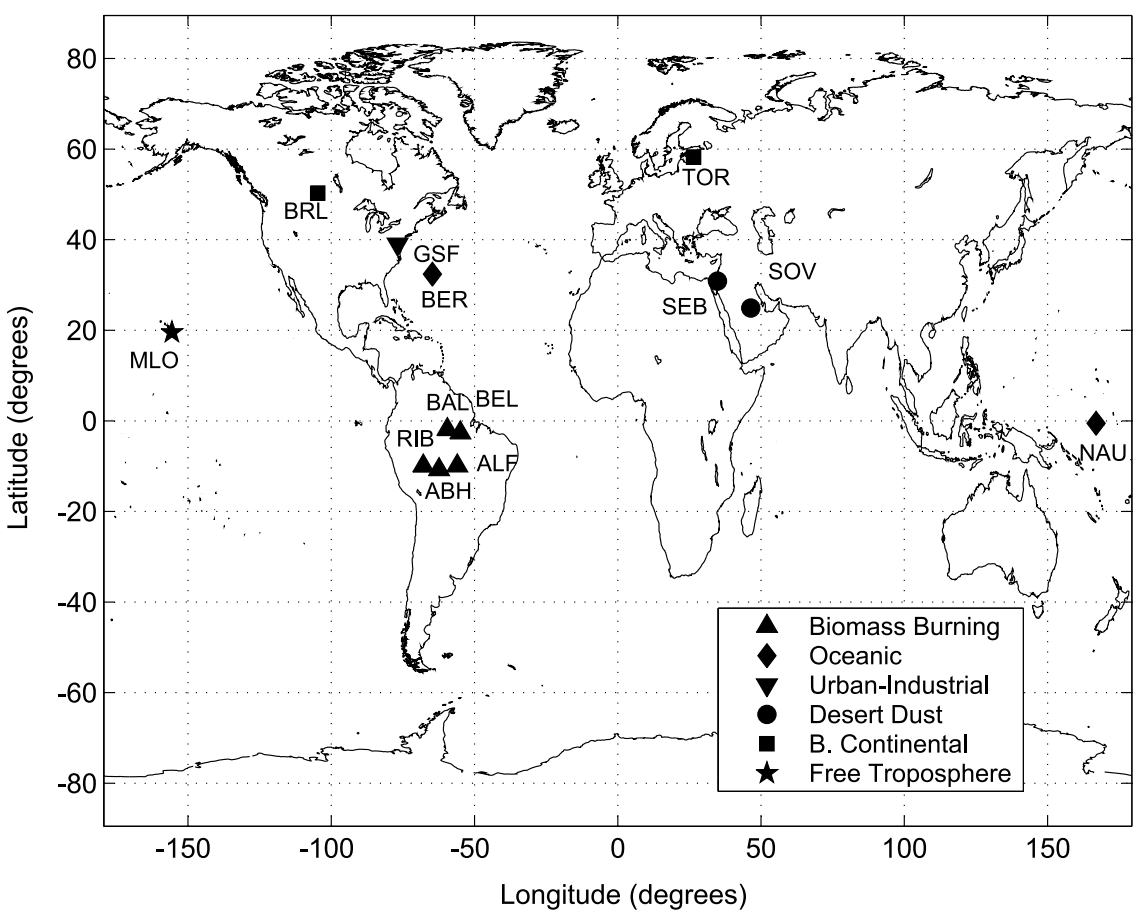

Figure 1. Distribution of the 13 ground-based stations used to validate AERONET aerosol radiative forcing and the main aerosol influences.

radiation levels. These atmospheric constituents are: urbanindustrial aerosols from populated industrial regions; biomass burning aerosols produced by forest and grassland fires; desert dust blown into the atmosphere by wind, background aerosols from continental zones and maritime aerosols from oceanic origin. Table 1 lists the location of each station as well as the available data set from the temporal collocation between AERONET and solar database (explained in detail in section 4), whereas Figure 2 shows the monthly mean of the aerosol optical depth, $\tau$, at $0.55 \mu \mathrm{m}$ for this data set. It is emphasized that the data in Figure 2 do not represent $\tau$ climatological values at these sites, but are the averages of $\tau$ observations that match the cloud screened downwelling solar irradiance data.

[15] The Brazilian stations (Alta Floresta, Abracos Hill, Rio Branco, Belterra, and Balbina), belonging to the SolRadNet, were established in Brazil as part of the Large-Scale Biosphere-Atmosphere Experiment in Amazonia (LBA) project to characterize the aerosol and solar radiation climatology of one of the world's most vital ecosystems [Schafer et al., 2002a]. This region is under the influence of highly absorbing aerosols [Dubovik et al., 2002a; Schafer et

Table 1. Altitude, Longitude, and Latitude of the Ground-Based Stations Used ${ }^{\mathrm{a}}$

\begin{tabular}{|c|c|c|c|c|c|c|c|}
\hline Station & $\begin{array}{c}\text { Longitude } \\
\text { (deg) }\end{array}$ & $\begin{array}{l}\text { Latitude } \\
\text { (deg) }\end{array}$ & $\begin{array}{l}\text { Altitude } \\
(\mathrm{m})\end{array}$ & $\begin{array}{c}\text { Instrumentation } \\
\text { and Spectral } \\
\text { Range }(\mu \mathrm{m})\end{array}$ & Aerosol Influences & $\mathrm{N}$ & Years \\
\hline Mauna Loa (MLO) & -155.58 & 19.54 & 3397 & CMS, $0.285-2.8$ & Free troposphere & 380 & $1999-2003 ; 2005-2006$ \\
\hline Bermuda (BER) & -64.70 & 32.37 & 10 & E-PSP, $0.285-2.8$ & Mixed oceanic & 63 & $1996-2002$ \\
\hline Nauru Island (NAU) & 166.92 & -0.52 & 7 & E-PSP, $0.285-2.8$ & Oceanic & 20 & 1999-2002 \\
\hline Bratts Lake (BRL) & -104.70 & 50.28 & 586 & $K \& Z, 0.305-2.8$ & Background continental & 456 & $1999-2001 ; 2003$ \\
\hline Toravere (TOR) & 26.46 & 58.25 & 70 & $K \& Z, 0.305-2.8$ & Background continental & 173 & $2002-2004$ \\
\hline Sede Boker (SEB) & 34.78 & 30.85 & 480 & E-PSP, $0.285-2.8$ & Desert dust & 1590 & $2003-2005$ \\
\hline Solar Village (SOV) & 46.41 & 24.91 & 650 & E-PSP, $0.285-2.8$ & Desert dust & 1013 & $2001-2002^{b}$ \\
\hline Alta Floresta (ALF) & -56.02 & -9.92 & 175 & $K \& Z, 0.305-2.8$ & Biomass burning & 83 & $1999-2003$ \\
\hline Abracos Hill (ABH) & -62.36 & -10.76 & 200 & $K \& Z, 0.305-2.8$ & Biomass burning & 85 & $1999-2004$ \\
\hline Balbina (BAL) & -59.49 & -1.92 & 80 & $K \& Z, 0.305-2.8$ & Biomass burning & 15 & $1999-2000$ \\
\hline Belterra (BEL) & -54.95 & -2.65 & 70 & $K \& Z, 0.305-2.8$ & Biomass burning & 32 & $1999-2003$ \\
\hline Rio Branco (RIB) & -67.87 & -9.96 & 212 & $K \& Z, 0.305-2.8$ & Biomass burning & 29 & $2000 ; 2002$ \\
\hline GSFC (GSF) & -76.84 & 38.99 & 87 & $K \& Z, 0.305-2.8$ & Urban-industrial & 227 & $2003-2006$ \\
\hline
\end{tabular}

${ }^{\mathrm{a}} \mathrm{N}$ is the total number of data considered for each place, which have verified the temporal constriction ( 30 seconds) and the cloud screened filter. The Mauna Loa data are from Solar Radiation's group from Mauna Loa Observatory and they were obtained by the component sum method (CMS). The second group of stations, with six cases, belongs to the BSRN network, where Kipp and Zonen CM-21 (K\&Z) and Eppley PSP (E-PSP) pyranometers were employed. In the last group, belonging to the SolRad-Net with six places, only Kipp and Zonen CM-21 (K\&Z) instruments were used.

${ }^{\mathrm{b}}$ The total available period is from 1999 to 2002 , but for this study only two years were selected. 
a)

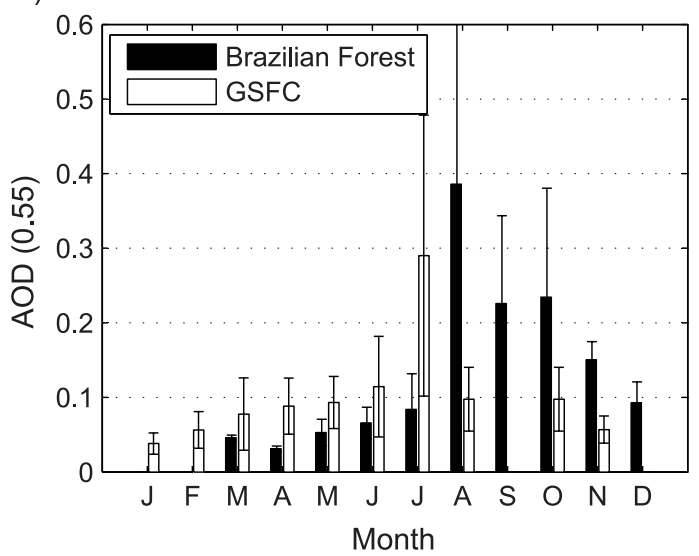

c)

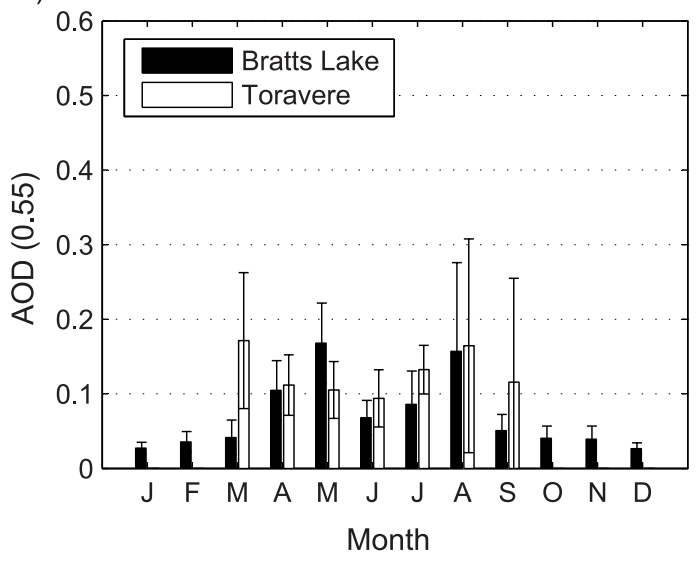

b)

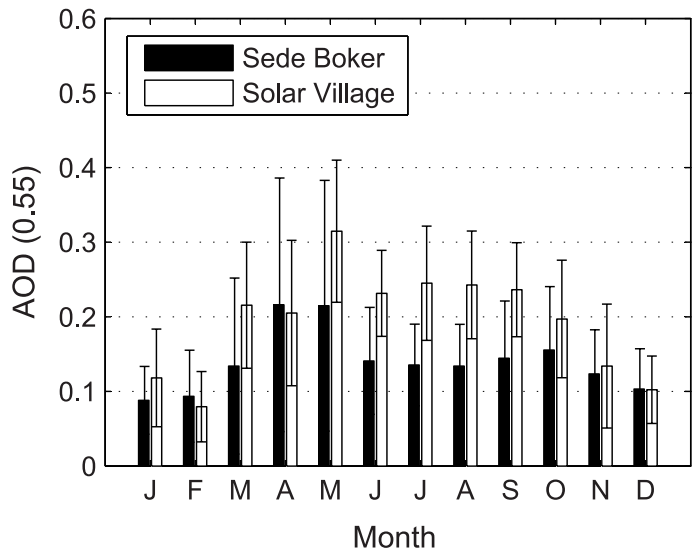

d)

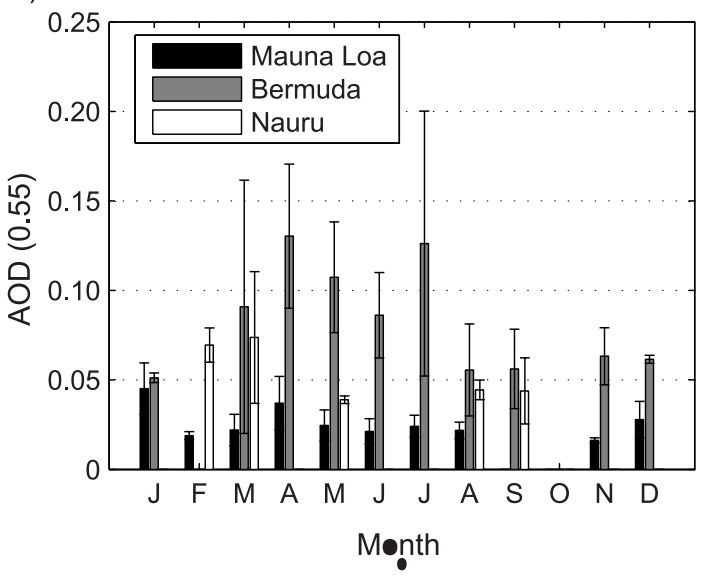

Figure 2. Monthly mean of aerosol optical depth, AOD or $\tau$, at $0.55 \mu \mathrm{m}$ for the data set of measurements shown in Table 2. (a) Forest smoke and urban-industrial, (b) desert dust, (c) background continental, and (d) oceanic and free troposphere. The error bars indicate one standard deviation.

al., 2002a, 2008], which are mainly produced from biomass-burning in the dry season in southern Amazonian forest, from August to October (Figure 2a). In this season aerosol optical depth measurements reach an order of magnitude greater than the values for non-burning months [Holben et al., 1998, 2001; Schafer et al., 2002a]. Given the proximity of the stations and they are influenced by the same type of aerosols, the Brazilian stations will be considered as a unique case in the current study, namely Brazilian forest.

[16] Goddard Space Flight Center (GSFC) station, belonging to SolRad-Net, was selected as representative of urban-industrial aerosols [Dubovik et al., 2002a]. It is located in suburban Washington D.C. and south of industrial Baltimore (Eastern US), so the most heavy industry is located to the north and local emissions are dominated by automobile traffic [Holben et al., 2001]. Pollution transported long distances is also present. Dubovik et al. [2002a] show that the haze at GSFC is the lowest absorbing aerosols, almost non-absorbing, compared to the other urban-industrial types analyzed, with values similar to oceanic conditions. With regards to the aerosol load (Figure 2a), the annual minimum is reached during the winter months, whereas the increase in the summer period is due predominately to anthropogenic sources both local, regional, and continental, processed by convection within humid relatively stagnant air masses [Holben et al., 2001].

[17] Solar Village and Sede Boker, BSRN stations, were selected as examples of mineral dust aerosols since they are located in desert environments. Solar Village is situated in the middle of the Arabian Peninsula, far away from the Persian Gulf or other industrialized areas. The remoteness of the area favors the study of the optical properties of desert dust aerosols, since the dust outbreaks are frequent especially in the spring period (Figure 2b) [Kaskaoutis et al., 2007]. On the other hand, Sede Boker is also located in a desert area, the northern part of the Israeli Negev desert, relatively far from local pollution sources; however, it lies at the crossroad between dust from the Sahara and the Arabian Peninsula and pollution from Europe [Formenti et al., 2001; Andreae et al., 2002; Gerasopoulos et al., 2003; Israelevich et al., 2003; Kubilay et al., 2003]. Despite its desert location, patterns of absorbing aerosols both dust and pollution aerosols have been observed at Sede Boker [Derimian et al., 2006]. At the Sede Boker site the dust events appear more frequently during the transition seasons and reach the annual maximums in April and May, whereas the summer period can be considered as relatively dust free [Ganor, 1994; Derimian et al., 2006]. Variability of monthly mean aerosol optical depth at $0.55 \mu \mathrm{m}$, for the analyzed in this study data set, is presented in Figure $2 \mathrm{~b}$. 
[18] Bratt's Lake and Toravere, both BSRN observatories, are located in non-industrial areas in the southern Canadian prairies and Eastern Europe, respectively, where the type of aerosols is generally of a background nature. As the presence of local anthropogenic pollution sources has no significance [McArthur et al., 2003; Russak et al., 2007], changes in aerosol content are mainly related to the transport of polluted air from more distant sources although there are episodic occurrences of forest-fire smoke. Also, in the case of Bratt's Lake there are registers of transcontinental dust, Asian dust plumes transported across the Pacific Ocean [Husar et al., 2001; Thulasiraman et al., 2002]. Thus, in both cases, the aerosol levels are relatively low during all year (Figure 2c), showing the highest values in summer time [McArthur et al., 2003; Russak et al., 2007].

[19] As examples of maritime environments two stations, located under different oceanic conditions, were considered: one placed in the Western Pacific Ocean, Nauru, and the other one in the Atlantic Ocean, Bermuda. Both observatories belong to the BSRN network. The first station is situated in the small island of Nauru, $40 \mathrm{~km}$ south of the equator, and under tropical regime. There is not any local pollution source, neither anthropogenic nor natural, and the site can be considered truly maritime [Smirnov et al., 2002], with aerosol levels constant during all year (Figure 2d). In the case of Bermuda, this archipelago is located in the Western North Atlantic Ocean relatively near to the US East Coast $(\sim 1000 \mathrm{~km})$ and under the influences of various aerosol sources. To Bermuda arrive relatively clean marine air masses from the central North Atlantic Ocean as well as pollutants and natural continental material from North America, Europe, and Africa [Smirnov et al., 2000a]. Thus, given its location, it can not always be considered as pure maritime but mixed or modified maritime because of the possible presence of dust, smoke, and urban-industrial aerosol [Smirnov et al., 2002]. Figure 2d shows the monthly average of $\tau$ at $0.55 \mu \mathrm{m}$ for the study data set, showing values relatively high values for a maritime site.

[20] Besides the five key aerosol types used in the current study, a station representative of clear atmosphere (quasi absence of atmospheric aerosols) has been selected. In this sense it is widely recognized the excellent conditions of the Mauna Loa Observatory, MLO, in order to characterize background atmosphere as well as for detecting variations both in solar irradiance and in atmospheric constituents (background and volcanic aerosols, trace gases, etc.) [e.g., Dutton and Bodhaine, 2001; Holben et al., 2001]. Factors contributing to the quality and representatives of the MLO are its remote location in the Pacific Ocean, far away from anthropogenic sources: it is situated on the north slope of Mauna Loa Volcano (Big Island of Hawaii); and its high elevation $\sim 3.4 \mathrm{~km}$ above sea level. Also, the presence of a strong marine temperature inversion layer, located below the station, often prevents the transport of possible polluted air to the free troposphere. With these conditions, the aerosol levels are very low (Figure 2d), and only they are slightly perturbed during the spring Asian dust season plus transport of Asian pollution and infrequent emissions from local volcanism [Holben et al., 2001]. Thus usual values of the multi-year annual mean for the aerosol optical depth at $0.50 \mu \mathrm{m}$ ranges from 0.015 to 0.020 [e.g., Holben et al.,
2001; García et al., 2006], and $0.029 \pm 0.013$ for the data set considered in the current work (see Table 2).

\section{Validation Methodology and AERONET Model Description}

[21] The AERONET Version 2.0 inversion products have incorporated valuable information about the direct solar effects of aerosols under cloud-free conditions, allowing to evaluate the global distribution of Earth's atmosphere radiative budget. The solar spectral $(\mathrm{F}(\lambda))$ and broadband fluxes (F) at the bottom and the top of the atmosphere (BOA and TOA, respectively), aerosol radiative forcing $(\Delta \mathrm{F})$ and aerosol radiative forcing efficiency $\left(\Delta \mathrm{F}^{\mathrm{eff}}\right)$ are currently available at any AERONET station. The AERONET aerosol radiative forcing is defined as the difference between the global solar irradiance with and without aerosols presence:

$$
\Delta \mathrm{F}_{\mathrm{BOA}}=\mathrm{F}_{\mathrm{BOA}}^{\downarrow}-\mathrm{F}_{\mathrm{BOA}}^{\downarrow 0} \quad \Delta \mathrm{F}_{\mathrm{TOA}}=-\left(\mathrm{F}_{\mathrm{TOA}}^{\uparrow}-\mathrm{F}_{\mathrm{TOA}}^{\uparrow 0}\right)
$$

where $\mathrm{F}$ and $\mathrm{F}^{0}$ are the broadband fluxes with and without aerosols, respectively, both at surface (BOA) and top of atmosphere (TOA). The arrows indicate the direction of the fluxes: $\downarrow \equiv$ downward flux and $\uparrow \equiv$ upward flux. This sign criterion implies that negative values of $\Delta F$ are associated to an aerosol cooling effect and positive to warming, both at the BOA and at the TOA. From this definition, the aerosol radiative forcing efficiency is defined as the rate at which the atmosphere is forced per unit of aerosol optical depth at $0.55 \mu \mathrm{m}$, both at BOA and TOA:

$$
\Delta \mathrm{F}_{\mathrm{BOA} / \mathrm{TOA}}^{\mathrm{eff}}=\Delta \mathrm{F}_{\mathrm{BOA} / \mathrm{TOA}} / \tau(0.55)
$$

This magnitude allows an evaluation of the direct radiative effect of each type of aerosol, characterized by size distribution and absorption (chemical composition), since the influence of aerosol load has been normalized.

[22] In order to use these radiative computations it is necessary to establish a level of accuracy for these values as well as to analyze the possible error sources. For validation of the AERONET broadband fluxes, and hence $\triangle F$ and $\Delta \mathrm{F}^{\mathrm{eff}}$ estimates, we have used extensive solar measurements from ground-based stations, Mauna Loa Observatory in addition to previously mentioned sites in the BSRN and SolRad-Net networks, influenced by different aerosols types and described in detail in sections 2 and 3. Only with ground-based measurements it is possible to directly validate the instantaneous downward broadband fluxes and hence $\Delta \mathrm{F}$ and $\Delta \mathrm{F}^{\mathrm{eff}}$ values at surface. However errors of the same order of magnitude are expected for these magnitudes at TOA, since the same methodology (aerosol and gaseous characterization, radiative model, ...) is applied to calculate the radiative magnitudes at BOA and TOA. Therefore, from now on, we will use the terms downward broadband and broadband fluxes indistinctly. Also, the aerosol radiative forcing $\Delta \mathrm{F}$ and forcing efficiency $\Delta \mathrm{F}^{\mathrm{eff}}$ are written without the subscript BOA hereafter. Even though the AERONET radiative transfer model has the capability to cover from 0.2 to $4.0 \mu \mathrm{m}$, in the current study the spectral, broadband fluxes and aerosol radiative forcing 
Table 2. Summary of Mean Values of AERONET Aerosol Optical Properties for Each Station, Which Have Verified the Temporal Constriction (30 Seconds) Between Measurements of Solar Database and AERONET ${ }^{\mathrm{a}}$

\begin{tabular}{|c|c|c|}
\hline & Brazilian Forest & GSFC \\
\hline $\begin{array}{l}\mathrm{N}(\omega, \mathrm{n}, \mathrm{k}) ; \mathrm{N}(\text { sphericity }) \\
\tau(0.55 \mu \mathrm{m}) \\
\text { Sphericity }(\%) \\
\omega(0.44 / 0.67 / 0.87 / 1.02 \mu \mathrm{m}) \\
\mathrm{n}(0.44 / 0.67 / 0.87 / 1.02 \mu \mathrm{m}) \\
\mathrm{k}(0.44 / 0.67 / 0.87 / 1.02 \mu \mathrm{m}) \\
\mathrm{r}_{\text {eff }}(\mu \mathrm{m})\end{array}$ & $\begin{array}{c}16 ; 39 \\
0.12 \pm 0.20 \\
98 ; 99 \\
0.93 / 0.91 / 0.89 / 0.88 \pm(0.02-0.03) \\
1.49 / 1.49 / 1.49 / 1.48 \pm(0.02-0.04) \\
0.013 / 0.012 / 0.011 / 0.011 \pm 0.003 \\
0.33 \pm 0.13 \\
\end{array}$ & $\begin{array}{c}3^{\mathrm{b}} ; 13 \\
0.07 \pm 0.05 \\
75 ; 98 \\
0.93 / 0.92 / 0.91 / 0.90 \pm(0.05-0.06) \\
1.51 / 1.50 / 1.51 / 1.51 \pm(0.10-0.11) \\
0.005 / 0.005 / 0.006 / 0.008 \pm(0.003-0.005) \\
0.40 \pm 0.22 \\
\end{array}$ \\
\hline & Solar Village & Sede Boker \\
\hline $\begin{array}{l}\mathrm{N}(\omega, \mathrm{n}, \mathrm{k}) ; \mathrm{N}(\text { sphericity }) \\
\tau(0.55 \mu \mathrm{m}) \\
\text { Sphericity }(\%) \\
\omega(0.44 / 0.67 / 0.87 / 1.02 \mu \mathrm{m}) \\
\mathrm{n}(0.44 / 0.67 / 0.87 / 1.02 \mu \mathrm{m}) \\
\mathrm{k}(0.44 / 0.67 / 0.87 / 1.02 \mu \mathrm{m}) \\
r_{\text {eff }}(\mu \mathrm{m}) \\
\end{array}$ & $\begin{array}{c}72 ; 621 \\
0.20 \pm 0.10 \\
10 ; 2 \\
0.92 / 0.94 / 0.95 / 0.95 \pm(0.03-0.05) \\
1.49 / 1.51 / 1.50 / 1.50 \pm 0.04 \\
0.005 / 0.004 / 0.003 / 0.004 \pm(0.006-0.008) \\
0.70 \pm 0.24 \\
\end{array}$ & $\begin{array}{c}53 ; 477 \\
0.14 \pm 0.10 \\
26 ; 5 \\
0.90 / 0.95 / 0.96 / 0.97 \pm(0.01-0.02) \\
1.50 / 1.52 / 1.50 / 1.49 \pm(0.04-0.05) \\
0.005 / 0.002 / 0.002 / 0.002 \pm 0.001 \\
0.53 \pm 0.18 \\
\end{array}$ \\
\hline$\underline{\mathrm{r}_{\mathrm{eff}}(\mu \mathrm{m})}$ & Bratts Lake & Toravere \\
\hline $\begin{array}{l}\mathrm{N}(\omega, \mathrm{n}, \mathrm{k}) ; \mathrm{N}(\text { sphericity }) \\
\tau(0.55 \mu \mathrm{m}) \\
\text { Sphericity }(\%) \\
\omega(0.44 / 0.67 / 0.87 / 1.02 \mu \mathrm{m}) \\
\mathrm{n}(0.44 / 0.67 / 0.87 / 1.02 \mu \mathrm{m}) \\
\mathrm{k}(0.44 / 0.67 / 0.87 / 1.02 \mu \mathrm{m}) \\
r_{\text {eff }}(\mu \mathrm{m})\end{array}$ & $\begin{array}{c}16 ; 75 \\
0.09 \pm 0.08 \\
83 ; 98 \\
0.96 / 0.94 / 0.93 / 0.92 \pm 0.01 \\
1.43 / 1.46 / 1.47 / 1.48 \pm 0.03 \\
0.005 \pm 0.001 \\
0.32 \pm 0.13 \\
\end{array}$ & $\begin{array}{c}7^{\mathrm{b}} ; 51 \\
0.12 \pm 0.08 \\
89 ; 99 \\
0.90 / 0.89 / 0.87 / 0.86 \pm(0.04-0.05) \\
1.42 / 1.43 / 1.43 / 1.43 \pm(0.05-0.06) \\
0.015 / 0.014 / 0.014 / 0.014 \pm(0.009-0.012) \\
0.42 \pm 0.29 \\
\end{array}$ \\
\hline$\underline{r_{\text {eff }}(\mu \mathrm{m})}$ & Nauru//Bermuda & Mauna Loa \\
\hline $\begin{array}{l}\mathrm{N}(\omega, \mathrm{n}, \mathrm{k}) ; \mathrm{N}(\text { sphericity }) \\
\tau(0.55 \mu \mathrm{m}) \\
\text { Sphericity }(\%) \\
\mathrm{r}_{\text {eff }}(\mu \mathrm{m})\end{array}$ & $\begin{array}{c}0 ; 0 / / 0 ; 7^{\mathrm{b}} \\
0.05 \pm 0.02 / / 0.09 \pm 0.05 \\
\mathrm{NA} / / 78 ; 94 \\
0.90 \pm 0.45 / / 0.43 \pm 0.20\end{array}$ & $\begin{array}{c}0 ; 0 \\
0.03 \pm 0.01 \\
\text { NA } \\
0.24 \pm 0.09 \\
\end{array}$ \\
\hline
\end{tabular}

${ }^{a}$ The values of aerosol optical depth $(\tau)$ and effective radius $\left(\mathrm{r}_{\text {eff }}\right)$ are given for the whole set of measurements (Table 1); whereas single scattering albedo $(\omega)$, complex refractive index ( $n$ and $k$ ), and sphericity parameter are given only for the quality criteria used in AERONET Version 2 Level 2 [V2.0-QAC]. It is noted that the uncertainty in retrieved single scattering albedo is quite high, typically $\gg 0.05$ at the low $\tau$ levels of the means given here. This parameter and the refractive indices are only reliably retrieved when $\tau(440) \geq 0.4$ [Dubovik et al., 2000, 2002a]. In the case of the sphericity parameter is also shown the median. For Nauru, Bermuda, and MLO there are no values of $\omega, \mathrm{n}$, and $\mathrm{k}$ that verify the quality criteria. The error assigned to each mean value is the standard deviation, $\sigma$, and NA means not available data.

${ }^{b}$ Notice the small data set and the hence the mean values must be taken into account carefully due to the low statistics significance of the results.

and forcing efficiency have been modeled just for spectral range measured by the solar databases $(\sim 0.3$ to $2.8 \mu \mathrm{m})$. Thus the exact uncertainty to reproduce the measured solar radiation is evaluated. Table 1 lists the available spectral ranges for each station.

[23] The AERONET broadband fluxes were calculated by spectral integration in the range from $\sim 0.3$ to $2.8 \mu \mathrm{m}$ using more than 200 size sub-intervals. In each of these subintervals the phase function was calculated using retrieved size distribution in the exact same manner as in AERONET retrieval scheme. The value of $\mathrm{n}(\lambda)$ and $\mathrm{k}(\lambda)$ were interpolated/extrapolated from the values $\mathrm{n}(\lambda)$ and $\mathrm{k}(\lambda)$ retrieved at AERONET wavelengths. Similarly, spectral dependence of surface reflectance is interpolated/extrapolated from surface albedo values assumed in the retrieval on the wavelengths of sun/sky-radiometer. Similarly to AERONET retrieval approach, the flux calculations were accounting for absorption and multiple scattering effects using the Discrete Ordinates DISORT approach [Stamnes et al., 1988; Nakajima and Tanaka, 1988]. The integration of atmospheric gaseous absorption and molecular scattering effects were conducted using developments employed in the Global Atmospheric ModEl (GAME) code [Dubuisson et al., 1996; Roger et al., 2006]. In the GAME code, gaseous absorption (mainly $\mathrm{H}_{2} \mathrm{O}$, $\mathrm{CO}_{2}$, and $\mathrm{O}_{3}$ ), is calculated from the correlated k-distribution [Lacis and Oinas, 1991]. The correlated k-distribution allows to account for interactions between gaseous absorption and multiple scattering with manageable computational time. Coefficients of the correlated k-distribution have been estimated from reference calculations using a line-by-line code [Dubuisson et al., 2004]. Regarding to the gaseous content in column, the instantaneous water vapor content retrieved by AERONET, using the absorption differential method at the $0.94 \mu \mathrm{m}$ channel [Smirnov et al., 2004] has been employed, whereas the total ozone content was taken from monthly climatology values (1978-2004) based on the NASA Total Ozone Mapping Spectrometer (TOMS) measurements [http://jwocky.gsfc.nasa.gov/]. The GAME model accounts for spectral gaseous absorption: ozone in the ultraviolet-visible spectral range $(0.20-0.35 \mu \mathrm{m}$ and $0.5-0.7 \mu \mathrm{m})$ and water vapor in the shortwave infrared spectrum $(0.8-3.0 \mu \mathrm{m})$. The atmospheric gaseous profile, US standard 1976 atmosphere model, was scaled to match with the gaseous concentrations in column. The GAME code has a fixed spectral resolution of $100 \mathrm{~cm}^{-1}$ from 2500 to $17700 \mathrm{~cm}^{-1}$ (4 to $0.6 \mu \mathrm{m}$ ) and $400 \mathrm{~cm}^{-1}$ from $17700 \mathrm{~cm}^{-1}$ to $50000 \mathrm{~cm}^{-1}$ (0.6 to $\left.0.2 \mu \mathrm{m}\right)$.

[24] The appropriate characterization of the surface albedo is a critical issue to estimate the aerosol radiative effect [e.g., Myhre et al., 2003; Abel et al., 2005] as well as an error source in the retrieval of aerosol properties [Dubovik et al., 2000; Sinyuk et al., 2007]. For that reason, one of the most 


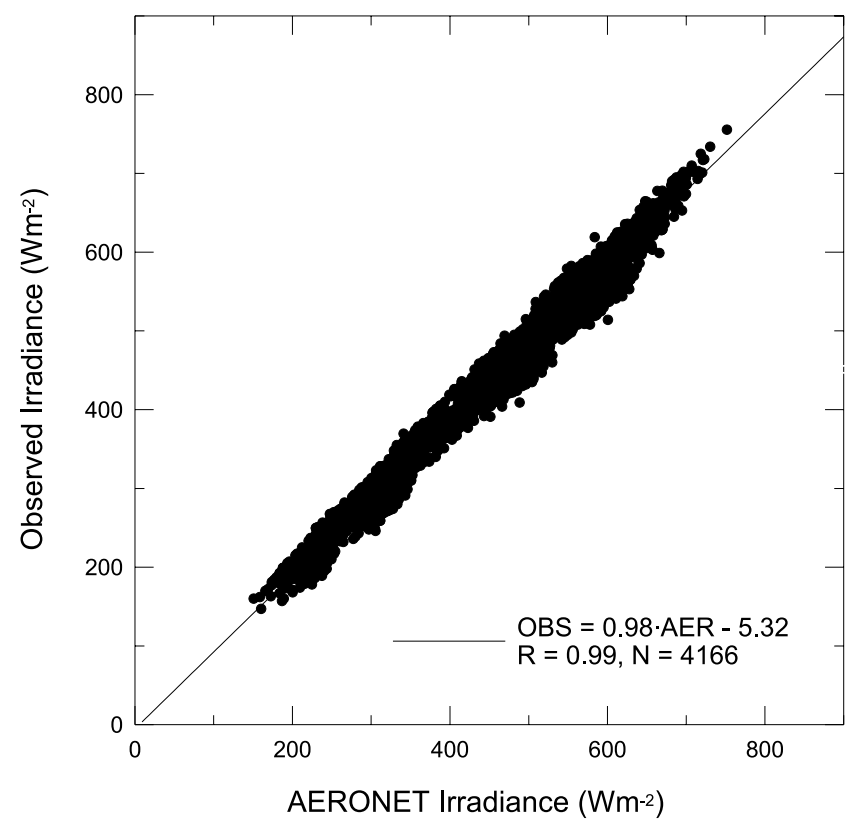

Figure 3. Observed irradiance versus irradiance modeled with AERONET inputs at the bottom of atmosphere, considering all stations. The errors in the parameters of the lineal fit are given in Table 3.

important improvements in Version 2.0, regarding Version 1.0 , is the assumption of a dynamic spectral and spatial satellite and model estimation of the surface albedo, including the bidirectional reflectance distribution function (BRDF), in the place of an assumed surface reflectivity [Dubovik et al., 2000]. Thus the BRDF Cox-Munk model over water [Cox and Munk, 1954] was used, which takes into account the wind effect over water using the wind speed data from NCEP/NCAR database (NOAA National Weather Service NOMADS NCEP server). For land surface covers, the Lie-Ross model was adopted [Lucht and Roujean, 2000], where the BRDF parameters are taken from the MODIS Ecotype generic BRDF models for vegetation, snow and ice [Nolin et al., 1998; Hall et al., 2002; Moody et al., 2005].

[25] Thus, the AERONET calculation of broadband radiation is focused on accurate accounting for the spectral dependence of the aerosol optical properties and surface albedo used as inputs. Recent studies showed that both to neglect completely the spectral dependence and consider only specific spectral range of aerosol properties are important error sources. These studies found uncertainties up to $30 \%$ for total aerosol radiative effect, combining the spectral influence and solar zenith angle variation [Myhre et al., 2003; Zhou et al., 2005]. Also, it should be noted that in difference with simplified approaches (accounting only asymmetry of phase function) flux calculations employed in AERONET processing use the detailed phase function (12 moments).

[26] In order to ensure that solar radiation and AERONET retrievals correspond to the same atmospheric conditions, only measurements with a temporal difference less than or equal to 30 seconds between solar database and AERONET have been considered. Table 2 shows a summary of the
AERONET aerosol optical properties for each station, which have verified this temporal constrain. It is noted that the uncertainty in retrieved single scattering albedo is quite high, typically $\gg 0.05$ at the low $\tau$ levels of the means given here. This parameter and the refractive indices are only reliably retrieved when $\tau(440) \geq 0.4$ [Dubovik et al., 2000, 2002a]. Given the high temporal resolution of solar radiation measurements (one minute), the data set for each station has been determined from the available AERONET measurements, quality assured and cloud screened (Level 2) [Smirnov et al., 2000b; AERONET's Version 2.0 quality assurance criteria (hereafter V2.0-QAC)]. Besides inversion assumptions of particle shape distributions and the use of improved surface albedo, the AERONET's Version 2.0 quality assurance criteria have been revised compared to Version 1.0. V2.0-QAC explains in detail the modifications introduced, as the calibration check or the dynamic residual error check.

\section{Results and Discussion}

\subsection{Broadband Fluxes}

[27] The comparison of measured and AERONET modeled downward broadband fluxes is shown in Figure 3 considering all stations, whereas Table 3 lists the summarized results of these comparisons, in terms of bias, root mean square error, slope of the least-square fit and correlation coefficient for each station. Overall the comparison shows a convincing agreement with the solar broadband fluxes highly correlated ( $\mathrm{R} \geq 99 \%$ ), where the relation of observed to modeled irradiance ranges from 0.98 to 1.02 (least square slope).

[28] In order to quantify the level of accuracy we have introduced the differences between the AERONET modeled and observed irradiance, $\Psi$ (AER-OBS). A brief statistical summary for the differences distribution is also given in Table 3. In the case of considering all stations to estimate the uncertainties of the solar broadband fluxes, $\Psi$ varies from -11 to $51 \mathrm{Wm}^{-2}$ (percentiles 5 and 95 of $\Psi$ distribution), where the mean $\Psi$ is $16 \pm 19 \mathrm{Wm}^{-2}$. In relative terms, the AERONET model overestimates the measured solar radiation, on average, by $4.0 \pm 5.2 \%$, value obtained from the ratio of AERONET modeled irradiance divided by observed one. These differences could be attributed, partly, to the combination of errors such as cosine response, calibration, linearity, ..., in the pyranometer measurements. All these sources of errors usually give uncertainties less than $3 \%-5 \%$ of the instantaneous instrument signal [Dutton et al., 2001, and references herein]. Given the solar zenith angle range used to AERONET sky measurements $\left(50^{\circ}-\right.$ $80^{\circ}$ ), one of the most influencing factor is the non-ideal angular response of this type of instruments, which limits their accuracy to about $3 \%$, or $20-30 \mathrm{Wm}^{-2}$, for instantaneous clear-sky measurements [Michalsky et al., 1999]. In particular, for the pyranometers used by the solar networks (Eppley and Kipp\&Zonen), this angular response can generate maximum deviation up to $\pm 3 \%$ from ideal case at $70^{\circ}-80^{\circ}$ sza in any azimuth direction (http://www.kippzonen.com/ and http://www.eppleylab.com/). This effect would result in measured flux that is biased low relative to true flux [Michalsky et al., 1999], resulting thus the overestimation observed in the AERONET solar broadband fluxes. The 
Table 3. Parameters of Lineal Regression Model $^{\mathrm{a}}$ and Residues ${ }^{\mathrm{b}}$

\begin{tabular}{|c|c|c|c|c|c|c|c|}
\hline Station & Slope $\pm \sigma$ & $\operatorname{Bias} \pm \sigma\left(\mathrm{Wm}^{-2}\right)$ & $\operatorname{RMS}\left(\mathrm{Wm}^{-2}\right)$ & $\mathrm{R}(\%)$ & $\Psi \pm \sigma\left(\mathrm{Wm}^{-2}\right)$ & Percentile 5,95 $\left(\mathrm{Wm}^{-2}\right)$ & $\varepsilon \pm \sigma(\%)$ \\
\hline Mauna Loa & $0.994 \pm 0.003$ & $+0.3 \pm 1.4$ & 9.50 & 99.78 & $2 \pm 10$ & $-16,13$ & $0.6 \pm 3.0$ \\
\hline Nauru & $0.979 \pm 0.020$ & $-2.7 \pm 9.7$ & 9.56 & 99.64 & $13 \pm 10$ & $-8,26$ & $2.7 \pm 2.2$ \\
\hline Bermuda & $1.021 \pm 0.016$ & $-17.7 \pm 7.9$ & 14.05 & 99.30 & $7 \pm 14$ & $-13,30$ & $2.1 \pm 3.9$ \\
\hline Bratts Lake & $1.000 \pm 0.003$ & $+2.3 \pm 1.1$ & 8.06 & 99.82 & $-2 \pm 8$ & $-17,9$ & $-0.6 \pm 2.3$ \\
\hline Toravere & $1.009 \pm 0.004$ & $-1.1 \pm 1.5$ & 6.53 & 99.90 & $-3 \pm 7$ & $-13,6$ & $-0.5 \pm 1.9$ \\
\hline Brazilian Forest & $1.008 \pm 0.007$ & $-9.2 \pm 3.5$ & 12.73 & 99.34 & $6 \pm 13$ & $-16,26$ & $1.5 \pm 3.2$ \\
\hline GSFC & $0.978 \pm 0.004$ & $-4.3 \pm 2.0$ & 9.56 & 99.76 & $14 \pm 10$ & $-5,32$ & $3.5 \pm 2.8$ \\
\hline Solar Village & $1.013 \pm 0.002$ & $-14.2 \pm 1.1$ & 8.95 & 99.75 & $8 \pm 9$ & $-8,23$ & $2.1 \pm 2.5$ \\
\hline \multirow[t]{2}{*}{ Sede Boker } & $0.989 \pm 0.003$ & $-28.5 \pm 1.5$ & 14.74 & 99.25 & $34 \pm 15$ & 10,57 & $8.5 \pm 4.8$ \\
\hline & $0.988 \pm 0.003^{\mathrm{b}}$ & $-9.9 \pm 1.1^{\mathrm{b}}$ & $10.07^{\mathrm{b}}$ & $99.63^{\mathrm{b}}$ & $16 \pm 10^{\mathrm{b}}$ & $0,33^{\mathrm{b}}$ & $3.7 \pm 2.6^{\mathrm{b}}$ \\
\hline \multirow[t]{2}{*}{ All Stations } & $0.976 \pm 0.002$ & $-5.3 \pm 1.0$ & 18.47 & 99.01 & $16 \pm 19$ & $-11,51$ & $4.0 \pm 5.2$ \\
\hline & $0.987 \pm 0.001^{\mathrm{b}}$ & $-2.6 \pm 0.6^{\mathrm{b}}$ & $11.59^{\mathrm{b}}$ & $99.61^{\mathrm{b}}$ & $9 \pm 12^{\mathrm{b}}$ & $-11,27^{\mathrm{b}}$ & $2.1 \pm 3.0^{\mathrm{b}}$ \\
\hline
\end{tabular}

${ }^{\mathrm{a}}$ Bias and slope of the least-square fit, its uncertainty at the $95 \%$ confidence interval (standard deviation, $\sigma$ ), root mean square error, $\mathrm{RMS}\left(\mathrm{Wm}{ }^{-2}\right.$ ), and correlation coefficient, R (\%), where the fit was evaluated considering the observed irradiance versus AERONET modeled irradiance.

${ }^{\mathrm{b}}$ Statistical parameters of the differences distribution: mean $\Psi$ (modeled menus observed irradiance), standard deviation of the distribution, $\pm \sigma$, and the percentiles 5 and 95 . The mean error, in relative terms $\varepsilon \pm \sigma(\%)$, was obtained from the ratio of AERONET modeled divided by observed irradiance. The sign minus in $\varepsilon$, for Bratts Lake and Toravere stations, means an underestimation of solar fluxes by AERONET calculations. In all stations, all cases are considered and NA means not available data.

differences can be observed in Figure 4, where $\Psi$ is displayed as a function of the observed broadband flux, aerosol optical depth at $0.44 \mu \mathrm{m}$ and solar zenith angle under background continental, biomass burning and mineral dust aerosols. No significant dependences are observed and the absolute differences can be considered practically constant for all the ranges of the irradiance (Figure 4a); whereas a smooth increase of $\Psi$ for high $\tau$ was noticed (Figure 4b). In global terms, variations from $16 \pm 19$ to $19 \pm 18 \mathrm{Wm}^{-2}$ in the mean $\Psi$ have been found between $\tau$ ranges, defined by $\tau(0.44 \mu \mathrm{m})<0.4$ and $\tau(0.44 \mu \mathrm{m}) \geq 0.4$, respectively. The lowest differences are observed for the clearest situations, with low aerosol load. It should be noted that $\tau(0.44 \mu \mathrm{m}) \geq 0.4$ is the recommended threshold by AERONET quality criteria for $\omega(\lambda), \mathrm{n}(\lambda)$ and $\mathrm{k}(\lambda)[$ Dubovik et al., 2000, 2002a; V2.0-QAC]. Thus the greatest uncertainties associated to $\omega(\lambda), \mathrm{n}(\lambda)$, and $\mathrm{k}(\lambda)$ values for low $\tau$ do not seem decisive in the solar fluxes simulations due to modest impact of atmospheric aerosols. With regard to solar zenith angle, no significant conclusion can be derived from Figure $4 \mathrm{c}$, since a very variable behavior was observed.

[29] The AERONET overestimation is also observed analyzing the ground-based stations separately, except for the locations under background aerosols, Bratt's Lake and Toravere, where the AERONET model slightly underestimates the observed irradiance, $\sim 2-3 \mathrm{Wm}^{-2}$ (see Table 3). Likewise under clear atmosphere conditions, MLO, the concordance is excellent with a bias equal to $+0.3 \pm$ $1.4 \mathrm{Wm}^{-2}$ obtained from the fit intercept. The MLO aerosol optical depth levels analyzed in this work were always lower than $0.1(\tau$ at $0.55 \mu \mathrm{m})$ and, in particular, the multiyear annual mean of $\tau$ was $0.03 \pm 0.01$ for the study database. The differences at MLO are clearly limited within $\pm 5 \%$ as well as there is neither any underestimation nor overestimation by AERONET results. Indeed the mean $\Psi$ is $2 \pm 10 \mathrm{Wm}^{-2}$ for the whole period of measurements and, on average, we can assume a difference only of $0.6 \pm 3.0 \%$ in the simulation of the observed solar radiation at MLO. This value encompasses perfectly the dispersion observed in the station. For the rest of stations, the mean differences range from $6 \mathrm{Wm}^{-2}$, obtained in Brazilian station, up to $34 \mathrm{Wm}^{-2}$ found in the Sede Boker station.

[30] The main location that contributes to the overall AERONET overestimation is Sede Boker, where it was obtained an overestimation of the observed fluxes of $34 \pm$ $15 \mathrm{Wm}^{-2}$, doubling the mean dispersion observed for the rest of stations. This station is under the influence of mineral dust and possible mixing with anthropogenic aerosols [Derimian et al., 2006]. Note the relatively low single scattering albedo of 0.90 at $0.44 \mu \mathrm{m}$ (Table 2), which could not be associated with the presence of pure mineral dust only. The large errors at Sede Boker that occur even at low $\tau$ strongly suggest a bias in the measured solar irradiance at that site, since varying the aerosol properties and surface albedo will not change the fluxes enough to agree with the measurements. In order to test it, we have checked the differences on the validation results, considering the solar radiation by means of combined sum of direct and diffuse irradiance. This quantity, as it was mentioned in section 2.1, is available only for the BSRN locations. In such conditions, the mean $\Psi$ (AER-OBS) decreased $\sim 50 \%$ from $34 \pm$ $15 \mathrm{Wm}^{-2}$ up to $16 \pm 10 \mathrm{Wm}^{-2}$, which shows clearly some experimental problem in the setup of the single pyranometer. In fact, a bias of $-21 \mathrm{Wm}^{-2}$ was found in pyranometer measurements regarding the sum values, with a relation between both measurements of 1 . As result, the fit parameters of solar comparison improve noticeably because of the important weight of this station on total data, as it can be observed in Table 3 . In fact, the mean $\Psi$, considering all stations, decreases about $44 \%$ giving $9 \pm 12 \mathrm{Wm}^{-2}$.

[31] In addition to the measurements uncertainty due to the cosine effect, the uncertainty in surface albedo and BRDF, assumed by AERONET, must also be considered as an error source in the modeled downwelling fluxes. This is especially true for the locations dominated by mineral dust (Sede Boker and Solar Village), where the surface albedo is usually quite bright. In such conditions, the values managed in AERONET can be higher than real ones, providing an overestimation of the observed irradiance as it was shown previously. This artifact will be more pronounced for high aerosol load due to the multiple scattering 
a)

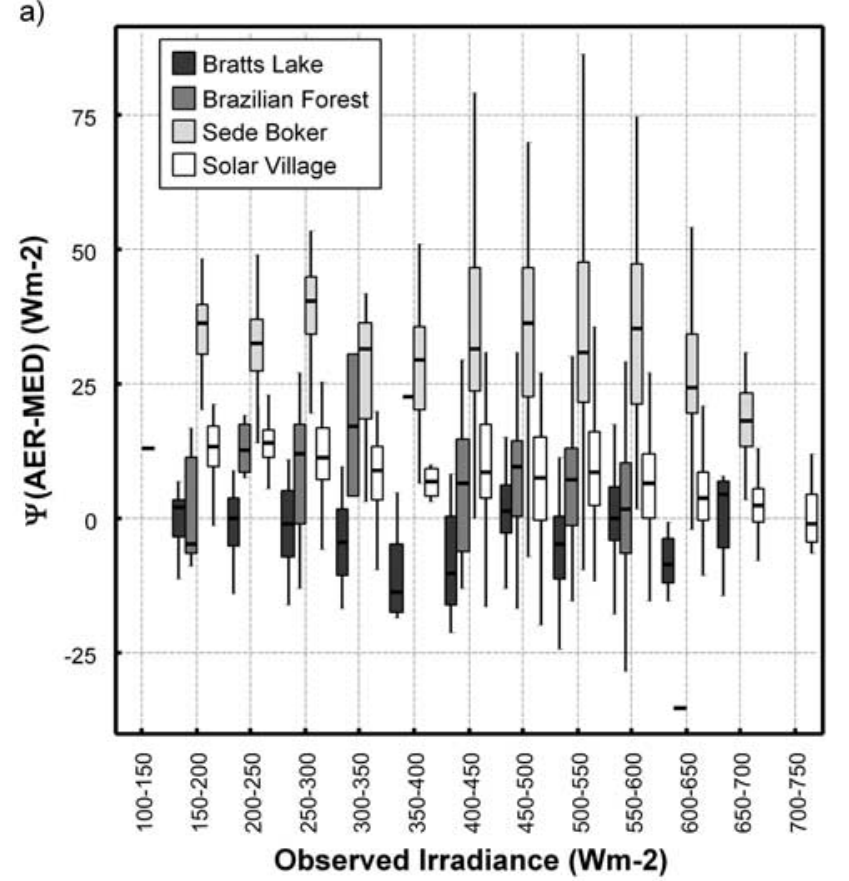

b)

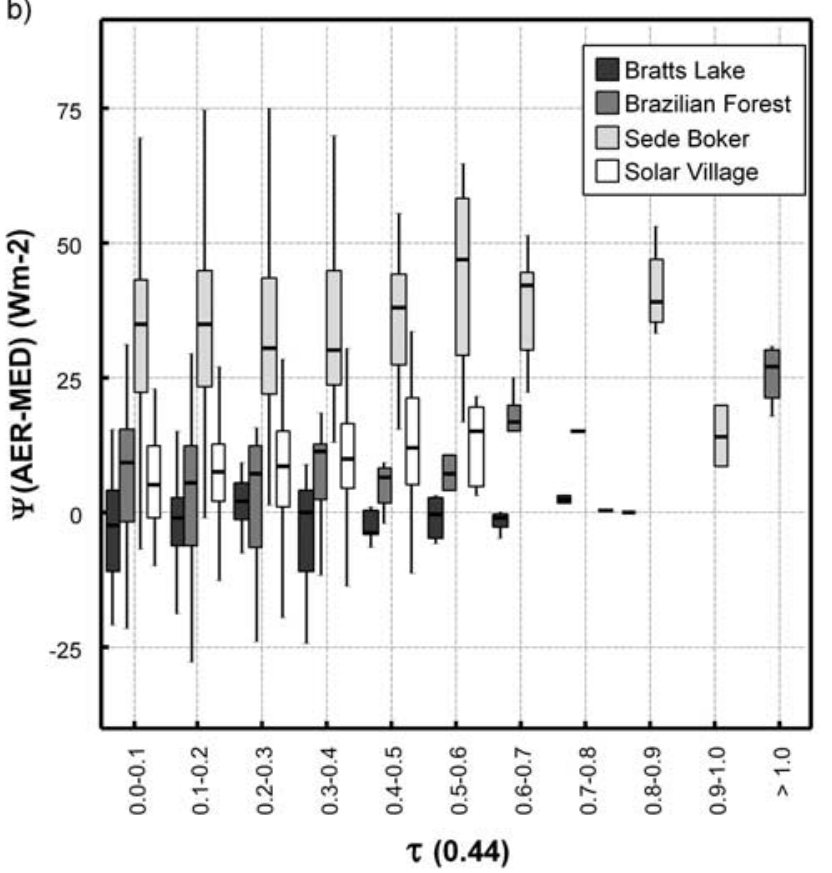

c)

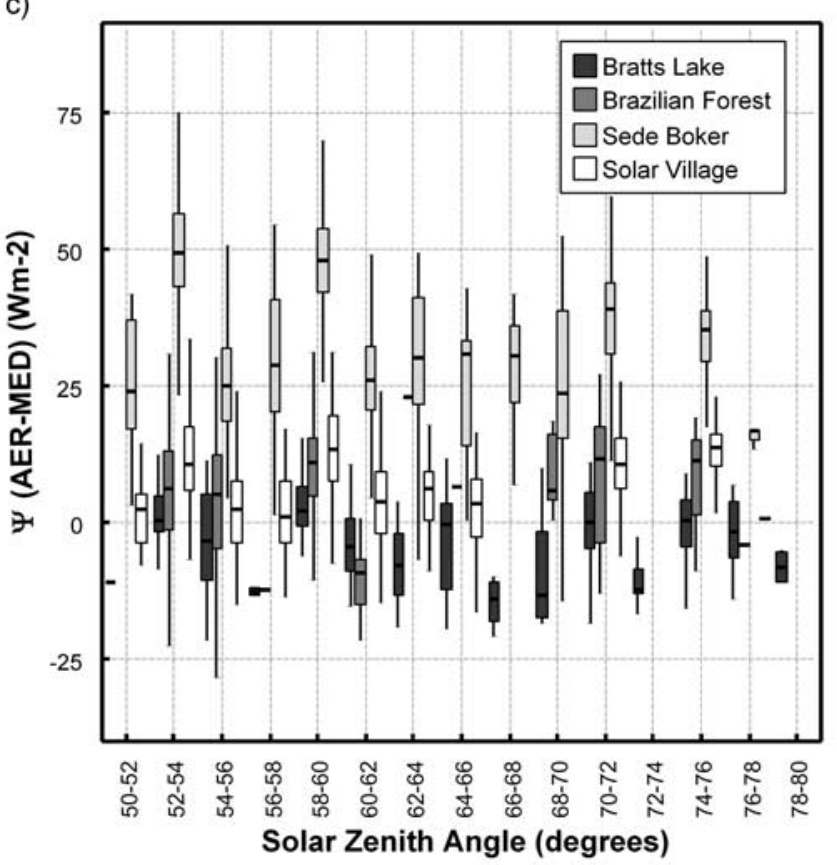

Figure 4. Differences between AERONET modeled and observed irradiance, $\Psi\left(\right.$ AER-OBS) $\left(\mathrm{Wm}^{-2}\right)$, versus (a) observed irradiance, (b) aerosol optical depth at $0.44 \mu \mathrm{m}$, and (c) solar zenith angle (degrees) under background continental, biomass burning, and desert dust aerosols. Lower and upper boundaries for each box are the 25 and 75 percentiles and the solid line is the median value. The whiskers encompass 1.5 times the range of the box.

processes. Figure 5 shows $\Psi$ as a function of the surface albedo at $0.87 \mu \mathrm{m}$ for the desert dust locations. As it can be observed, the differences in the broadband fluxes are higher for more bright surfaces, when the effect of the surface albedo values has a more important impact on flux calculation. Also, Bratts Lake station was displayed as example of situations where this behavior was not observed so clearly. Besides the uncertainties in the surface albedo for large solar zenith angles must be taken into account in the error interpretation.

[32] Model assumptions as the homogeneous aerosol vertical structure assumed in AERONET retrievals can be considered also as sources of uncertainties; however the 


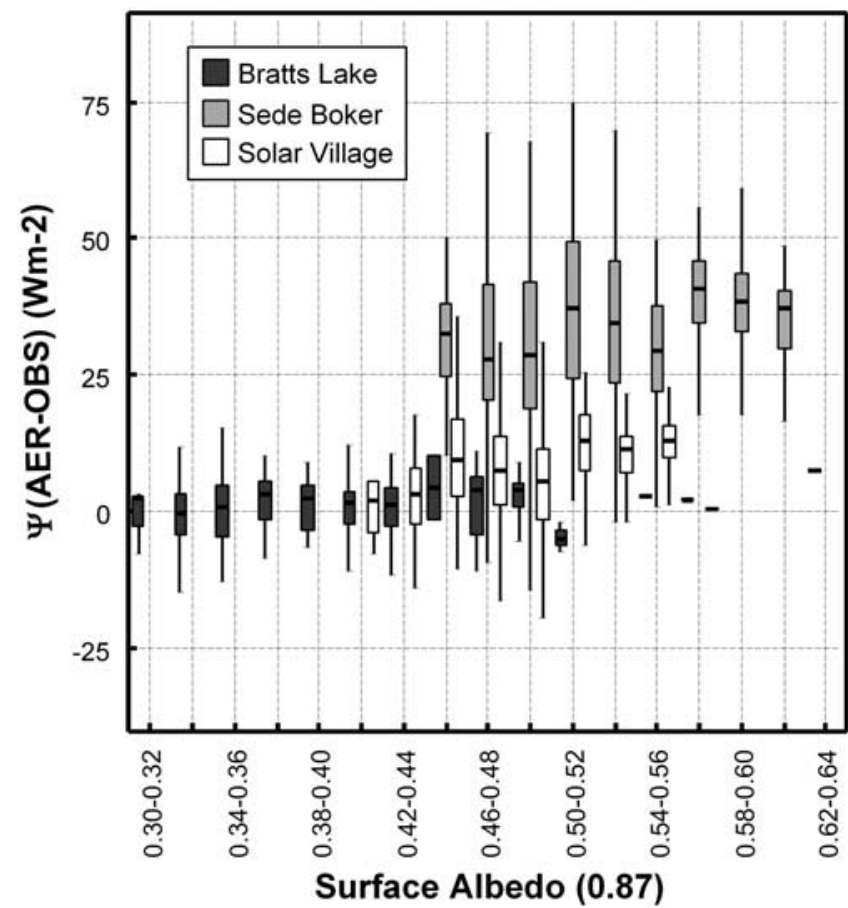

Figure 5. Differences between AERONET modeled and observed irradiance, $\Psi$ (AER-OBS) $\left(\mathrm{Wm}^{-2}\right)$, for stations influenced by desert dust and background continental as function of the surface albedo at $0.87 \mu \mathrm{m}$. The boxes and whiskers are defined as Figure 4.

effect of these errors is minor in most cases [Dubovik et al., 2000]. The flux calculations are performed for multi-layered atmosphere with US standard atmosphere model for gaseous distributions and single fixed aerosol vertical distribu-

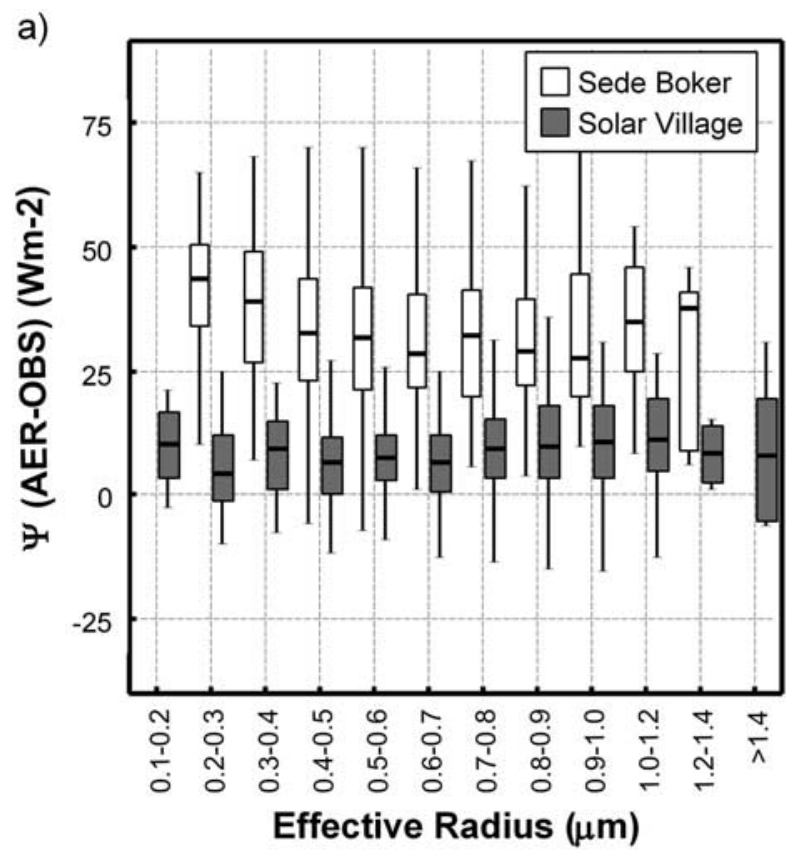

tion (exponential with aerosol height of $1 \mathrm{~km}$ ). The deviations of these assumptions from the reality are also potential source of errors, although, our tests did not show any significant sensitivity of flux estimates to these assumptions. Differences less than $1 \mathrm{~W} / \mathrm{m}^{2}$ due to different vertical profiles were observed on the downward solar flux at the bottom of the atmosphere. The sensitivity tests were conducted for $\tau(0.55 \mu \mathrm{m})=0.1,0.5$ and 1.0 , and separately for the two aerosol types observed at the station with higher uncertainties, Sede Boker station: (1) size distribution with dominant coarse mode and increased absorption at $440 \mathrm{~nm}$ (mineral dust conditions) and (2) bimodal size distribution, absorbing aerosols (anthropogenic situation). These differences are negligible $(\sim 0.2-3 \%)$ compared to instantaneous aerosol radiative forcing.

[33] Except the influence of surface albedo, $\Psi$ has not shown any significant sensitivity with other aerosol parameters analyzed as single scattering albedo at $0.44 \mu \mathrm{m}$ (data not shown). Also, the influences of the size and shape particles have been checked. As example, the results are displayed for the aerosols where these are more decisive, desert dust situations (Figures 6a and 6b). For the Solar Village site, $\Psi$ was totally independent of the effective radius $\left(\mathrm{r}_{\mathrm{eff}}\right)$. However, at the Sede Boker site, a slight dispersion associated with the smallest particles was found (Figure 6b). Regarding the aerosol shape, the non-sphericity parameterization is not a critical issue in the modeling of integral optical properties (single scattering albedo and asymmetry factor) and hence in the broadband fluxes calculation [Mishchenko et al., 1997], such as it can be observed in Figure 6b. At the same time, it should be noted that recently conducted sensitivity test showed that neglecting particle non-sphericity in calculation of broadband fluxes in presence of non-spherical dust result in minor

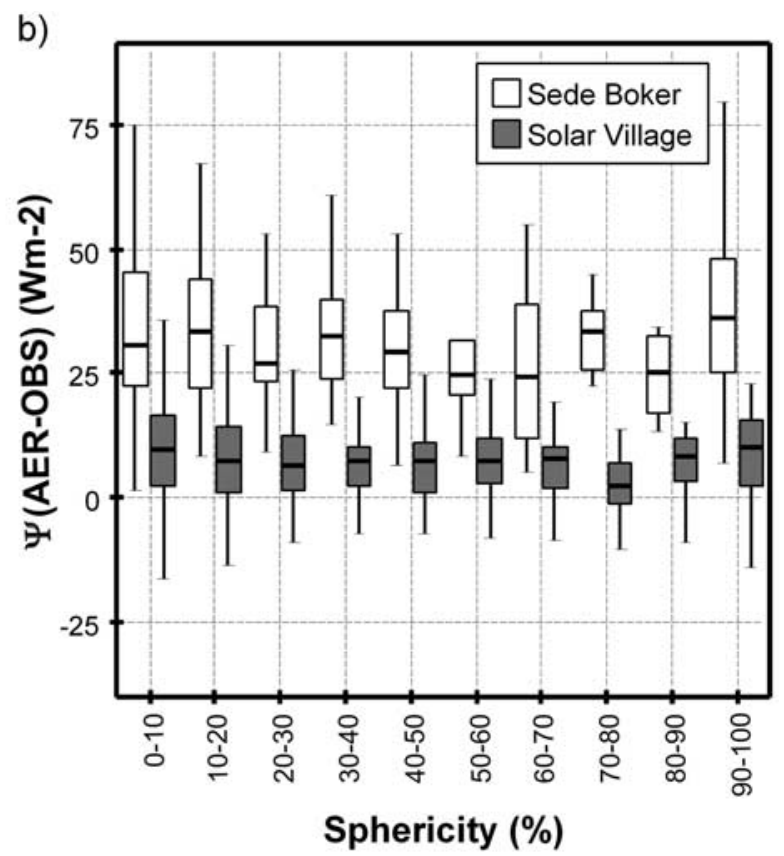

Figure 6. Differences between AERONET modeled and observed irradiance, $\Psi$ (AER-OBS) $\left(\mathrm{Wm}^{-2}\right)$, for stations influenced by desert dust and background continental as function of (a) effective radius $(\mu \mathrm{m})$ and (b) sphericity parameter (\%). The boxes and whiskers are defined as Figure 4. 


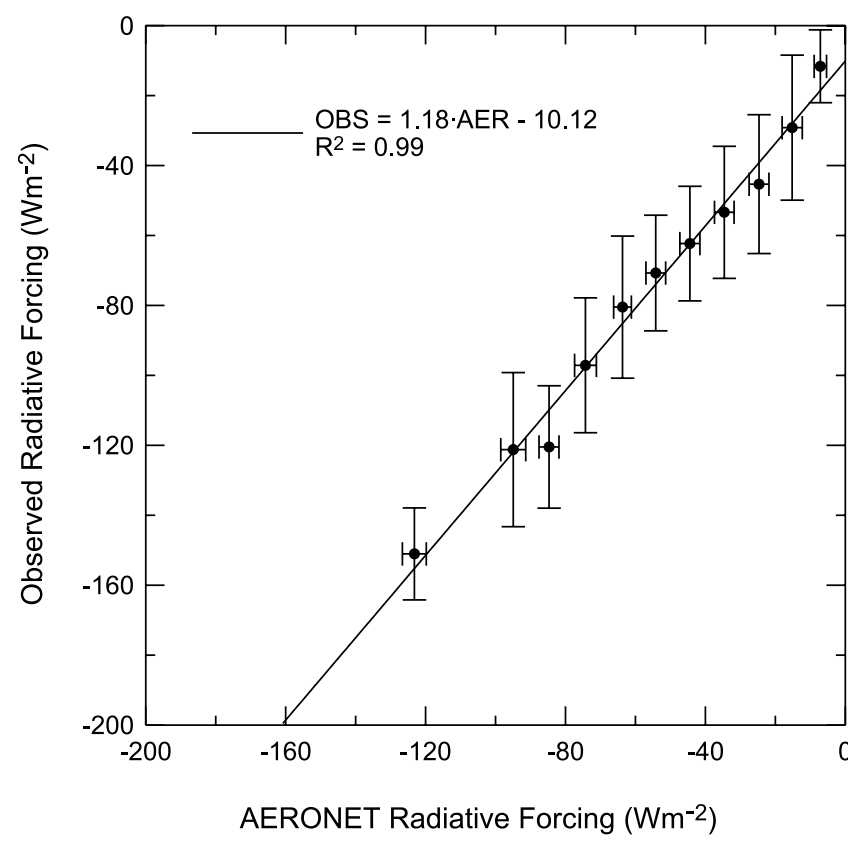

Figure 7. Observed versus AERONET radiative forcing $\left(\mathrm{Wm}^{-2}\right)$ at the bottom of the atmosphere, considering all stations. The AERONET $\triangle \mathrm{F}$ range was divided in bins of $10 \mathrm{Wm}^{-2}$ where the mean of the instantaneous observed and modeled $\Delta \mathrm{F}$ was computed. The standard deviation in each bin is shown by error bars.

but noticeable bias, up to $10 \%$ overestimation of daily average aerosol radiative effect [Derimian et al., 2008]. The plotted values of $\tau$ are given for the whole set of measurements (Table 1); whereas the sphericity parameter are valid only for the quality criteria used in AERONET Version 2 Level 2: $\tau(0.44 \mu \mathrm{m}) \geq 0.1$ and angstrom parameter $<1.2$ [V2.0-QAC].

\subsection{Aerosol Radiative Forcing and Aerosol Radiative Forcing Efficiency}

[34] The aerosol radiative forcing $(\Delta \mathrm{F})$ and forcing efficiency $\left(\Delta \mathrm{F}^{\mathrm{eff}}\right)$ have been determined according to the expressions (1) and (2), where the solar broadband fluxes without aerosols $\left(\mathrm{F}^{0}\right)$ were evaluated with AERONET radiative transfer model described in section 4 . For the observed $\Delta \mathrm{F}$ and $\Delta \mathrm{F}^{\mathrm{eff}}$, the solar broadband fluxes with aerosols $(\mathrm{F})$ were taken from the solar databases (pyranometer measurements), whereas the modeled $\Delta \mathrm{F}$ and $\Delta \mathrm{F}^{\mathrm{eff}}$ were computed considering $\mathrm{F}$ from AERONET simulations. Following the same methodology that for broadband fluxes, the error was estimated by means of the comparison of observed and modeled radiative magnitudes, and then the error propagation for the calculated $\Delta \mathrm{F}$ has been analyzed. The results are showed in Figure 7, where the observed $\Delta \mathrm{F}$ is plotted versus the AERONET $\Delta \mathrm{F}$ considering all stations. The regression fit was computed dividing the range of the instantaneous AERONET $\Delta \mathrm{F}$ in bins of $10 \mathrm{Wm}^{-2}$, where the mean of the instantaneous observed and modeled $\Delta \mathrm{F}$ was calculated to evaluate the regression model. These fit conditions provide the same weight for every bin in the regression model avoiding the greater weight for the smallest $\Delta \mathrm{F}$, whereas the points used have statistic significance. As it can be observed in Table 4, where the fit parameters of each location are listed, the comparison shows a noticeable agreement and the relation of observed to modeled $\Delta \mathrm{F}$ goes from 0.83 to 1.44 (least square slope). In particular, considering all stations, this coefficient was $1.18 \pm 0.05$ resulting in an overall bias of $+10.1 \pm 3.1 \mathrm{Wm}^{-2}$. Regarding to the solar broadband fluxes with aerosols $(\mathrm{F})$, a mean offset between modeled and measured irradiance was found for each location (see $\Psi$ values in Table 3 ), being these systematic errors used to correct the observed irradiance at each station. In such conditions, the combined uncertainties due to measurements and model calculations would be minimized. With this correction, the relation between observed and modeled $\Delta \mathrm{F}$ improves appreciably, $1.00 \pm$ 0.03 with a bias of $+0.7 \pm 2.0 \mathrm{Wm}^{-2}$, because of the reduction of the bias in each station separately. In particular, for Sede Boker the bias from the fit intercept decreases from $-35.3 \mathrm{Wm}^{-2}$ to $0.1 \mathrm{Wm}^{-2}$.

[35] The uncertainties in the aerosol radiative forcing $(\Delta \mathrm{F})$ have been estimated from the differences between the AERONET $\triangle \mathrm{F}$ minus the observed ones (DRF). Because of the definition of the $\Delta \mathrm{F}$ besides that the same values of $F^{0}$ have been considered to calculate the observed

Table 4. Parameters of Lineal Regression Model $^{\mathrm{a}}$ and Residues ${ }^{\mathrm{b}}$

\begin{tabular}{|c|c|c|c|c|c|c|c|}
\hline \multirow[b]{2}{*}{ Station } & \multirow[b]{2}{*}{ Slope $\pm \sigma$} & \multirow{2}{*}{$\begin{array}{l}\text { Bias } \pm \sigma \\
\left(\mathrm{Wm}^{-2}\right)\end{array}$} & \multirow{2}{*}{$\begin{array}{c}\text { RMS } \\
\left(\mathrm{Wm}^{-2}\right)\end{array}$} & \multirow{2}{*}{$\begin{array}{c}\mathrm{R} \\
(\%) \\
\end{array}$} & \multirow{2}{*}{$\begin{array}{c}\mathrm{DRF} \pm \sigma \\
\left(\mathrm{Wm}^{-2}\right)\end{array}$} & \multicolumn{2}{|c|}{$\mathrm{DRFE} \pm \sigma\left(\mathrm{Wm}^{-2} \tau_{0.55}{ }^{-1}\right)$} \\
\hline & & & & & & $\tau_{0.44}<0.4$ & $\tau_{0.44} \geq 0.4$ \\
\hline Mauna Loa & $0.83 \pm 0.13$ & $-2.6 \pm 1.5$ & 1.24 & 97.53 & $2 \pm 10$ & $101 \pm 379$ & NA \\
\hline Nauru & NA & NA & NA & NA & $13 \pm 10$ & $234 \pm 224$ & NA \\
\hline Bermuda & $1.37 \pm 0.33$ & $-0.9 \pm 5.6$ & 6.32 & 90.03 & $7 \pm 14$ & $91 \pm 214$ & NA \\
\hline Bratts Lake & $0.99 \pm 0.06$ & $+2.3 \pm 2.8$ & 3.95 & 98.79 & $-2 \pm 8$ & $-68 \pm 218$ & $-5 \pm 10$ \\
\hline Toravere & $0.86 \pm 0.07$ & $-0.7 \pm 2.7$ & 3.38 & 98.53 & $-3 \pm 7$ & $-20 \pm 84$ & $-30 \pm 18$ \\
\hline Brazilian Forest & $1.05 \pm 0.12$ & $-3.7 \pm 5.5$ & 7.63 & 96.45 & $6 \pm 13$ & $90 \pm 211$ & $24 \pm 15$ \\
\hline GSFC & $1.44 \pm 0.07$ & $-7.3 \pm 2.6$ & 2.65 & 99.62 & $14 \pm 10$ & $250 \pm 201$ & $85 \pm 18$ \\
\hline Solar Village & $1.05 \pm 0.03$ & $-5.9 \pm 1.3$ & 1.74 & 99.79 & $8 \pm 9$ & $51 \pm 81$ & $30 \pm 25$ \\
\hline \multirow[t]{2}{*}{ Sede Boker } & $1.00 \pm 0.05$ & $-35.3 \pm 3.3$ & 4.81 & 99.07 & $34 \pm 15$ & $335 \pm 224$ & $78 \pm 32$ \\
\hline & $1.04 \pm 0.06^{\mathrm{b}}$ & $-15.2 \pm 4.2^{\mathrm{b}}$ & $6.02^{\mathrm{b}}$ & $98.68^{b}$ & $16 \pm 10^{b}$ & $147 \pm 126^{b}$ & $42 \pm 27^{\mathrm{b}}$ \\
\hline \multirow[t]{2}{*}{ All Stations } & $1.18 \pm 0.05$ & $-10.1 \pm 3.1$ & 5.33 & 99.29 & $16 \pm 19$ & $164 \pm 267$ & $40 \pm 40$ \\
\hline & $1.09 \pm 0.02^{\mathrm{b}}$ & $-6.2 \pm 1.4^{b}$ & $2.41^{\mathrm{b}}$ & $99.83^{b}$ & $9 \pm 12^{b}$ & $88 \pm 200^{\mathrm{b}}$ & $28 \pm 30^{b}$ \\
\hline
\end{tabular}

${ }^{\mathrm{a}} \mathrm{Bias}$ and slope of the least-square fit, its uncertainty at the $95 \%$ confidence interval (standard deviation, $\sigma$ ), root mean square error, RMS (Wm ${ }^{-2}$ ), and correlation coefficient, $\mathrm{R}(\%)$, where the fit was evaluated considering the observed radiative forcing versus AERONET radiative forcing.

${ }^{\mathrm{b}}$ Statistical parameters of the differences distribution: mean difference radiative forcing, DRF (modeled minus measured $\Delta \mathrm{F}$, Wm ${ }^{-2}$ ), and mean difference radiative forcing efficiency, DRFE $\left(\mathrm{Wm}^{-2} \tau_{0.55}{ }^{-1}\right.$ ). The $\Delta \mathrm{F}^{\mathrm{eff}}$ values go up to $-600 \mathrm{Wm}^{-2} \tau_{0.55}{ }^{-1}$. The $\tau_{0.44}$ is at $0.44 \mu \mathrm{m}$. NA means not available data. 

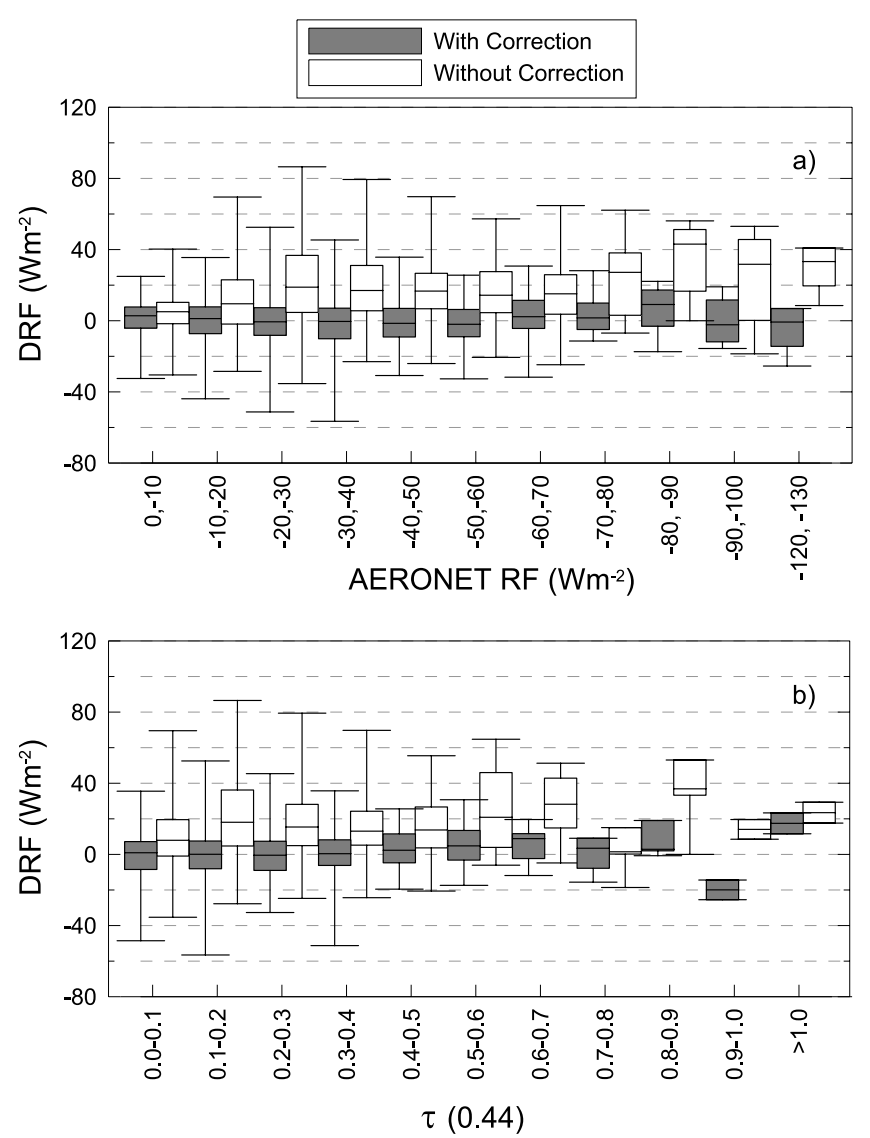

Figure 8. Differences between AERONET and observed radiative forcing (AER-OBS) $\left(\mathrm{Wm}^{-2}\right)$, both corrected by offset in the broadband fluxes, $\mathrm{DRF}_{\text {corr, }}$ and without correction, DRF, versus (a) AERONET radiative forcing, $\Delta \mathrm{F}\left(\mathrm{Wm}^{-2}\right)$, and (b) aerosol optical depth at $0.44 \mu \mathrm{m}$. The boxes are defined as Figure 4, but the whiskers encompass the maximum and minimum values of each range.

and AERONET $\triangle \mathrm{F}$, the differences for the radiative forcing and solar fluxes are the same, as it is shown in Table 4. In addition, DRF will show equal sensitivity to aerosol parameters like sphericity parameter, $\omega$ or $r_{\text {eff. Notice that if the }}$ correction of the systematic offset is applied, the mean differences between modeled and observed values go to zero. For instance, the mean error varies from $16 \pm 19 \mathrm{Wm}^{-2}$ to $0 \pm 12 \mathrm{Wm}^{-2}$ in the general case. This can be observed in Figure 8 where the DRF distribution is plotted, with and without correction, as function of the radiative forcing and aerosol load. Only the general case is displayed as example, however, the same tendency is observed under all types of aerosols studied. From these results, it is evidence that the $\Delta \mathrm{F}$ uncertainties are affected by the range of the aerosol load, showing the major errors for high aerosol load, where are located the highest $\Delta \mathrm{F}$ values. In such situations, the flux calculations are more sensitive to the influence of aerosols parameters uncertainties. The mean differences oscillate, on average, from $-2 \pm 8$ and $-3 \pm 7 \mathrm{Wm}^{-2}$ for background continental, $8 \pm 9$ to $34 \pm 15 \mathrm{Wm}^{-2}$ for desert dust, $14 \pm 10 \mathrm{Wm}^{-2}$ for urban-industrial, $6 \pm \mathrm{Wm}^{-2}$ in biomass burning, smaller than $13 \pm 10 \mathrm{Wm}^{-2}$ under oceanic aerosols and $2 \pm 10 \mathrm{Wm}^{-2}$ for clear conditions (Table 4). As it was shown in the fluxes comparisons, the elevated differences observed in Sede Boker station are attributed to experimental problems and a mean DRF of $16 \pm 10$ $\mathrm{Wm}^{-2}$ was found for this location. As result, the mean DRF, considering all stations, decreases noticeably from $16 \pm 19$ $\mathrm{Wm}^{-2}$ up to $9 \pm 12 \mathrm{Wm}^{-2}$ just like the fit parameters (see Table 4). For instance, the slope coefficient varies from $1.18 \pm 0.05$ to $1.09 \pm 0.02$.

[36] The uncertainties increase with high $\Delta \mathrm{F}$ because of the positive lineal relation that $\Delta \mathrm{F}$ and $\tau$ present; whereas for $\Delta \mathrm{F}^{\text {eff }}$ values the relation is the opposite one, given the definition of the $\Delta \mathrm{F}^{\text {eff }}$ (equation (2)). For that reason, the differences between observed and AERONET modeled $\Delta \mathrm{F}^{\text {eff }}$ (DRFE) were multiplied for small $\tau$, and the highest dispersion was obtained for situations with low aerosols levels. Therefore if we limited the analysis of $\Delta \mathrm{F}^{\text {eff }}$ to cases with the recommended threshold by AERONET quality criteria for $\omega(\lambda), \mathrm{n}(\lambda)$ and $\mathrm{k}(\lambda)$, i.e., $\tau(0.44 \mu \mathrm{m}) \geq 0.4$ [Dubovik et al., 2000, 2002a; V2.0-QAC], the obtained errors correspond to a more realistic situation. In such conditions, the mean DRFE varies from $-5 \pm 10 \mathrm{Wm}^{-2} \tau_{0.55}^{-1}$ for Bratts Lake station up to $85 \pm 18 \mathrm{Wm}^{-2} \tau_{0.55}^{-1}$ in GSFC; whereas a DRFE of $40 \pm 40 \mathrm{Wm}^{-2} \tau_{0.55}^{-1}$ was found considering all stations (see Table 4). If the correction of Sede Boker is taken into account, the overall mean DRFE decreases up to $28 \pm 30 \mathrm{Wm}^{-2} \tau_{0.55}^{-1}$.

[37] On literature, the aerosol forcing efficiency $\left(\Delta \mathrm{F}^{\text {eff }}\right)$ is usually evaluated through the slope method, giving an average $\Delta \mathrm{F}^{\mathrm{eff}}$ of the days used to compute it, whereas AERONET provides instantaneous $\Delta \mathrm{F}^{\text {eff }}$ values. Only when the same aerosols type is present, the $\Delta \mathrm{F}^{\text {eff }}$ computed with both methodologies should coincide. The main drawback to compare with other studies is the type of $\Delta \mathrm{F}^{\text {eff }}$ property reported in the literature. For example, many studies report diurnal average forcing efficiency, or an alternative methodology has been applied. Nevertheless $\Delta \mathrm{F}^{\text {eff }}$ with the slope method was evaluated considering the aerosol radiative forcing at surface and, on average, the same range of values was found. For instance, for Brazilian stations we have found $\Delta \mathrm{F}^{\text {eff }}=-131 \mathrm{Wm}^{-2} \tau_{0.55}^{-1}$ during biomass burning season (sza interval: $50-80^{\circ}$ ), value very close to the observed one by Schafer et al. [2002b], $-145 \mathrm{Wm}^{-2} \tau_{0.50}^{-1}$ for the same type of aerosols (sza interval: $25-35^{\circ}$ ). For stations under Asian mineral dust influences, Xia et al. [2007] found $\Delta \mathrm{F}^{\mathrm{eff}}$ of $-146 \mathrm{Wm}^{-2} \tau_{0.55}^{-1}$; whereas we have observed lowest values, $-121 \mathrm{Wm}^{-2} \tau_{0.55}^{-1}$, for Arabian stations during the dusty season. However the different mineralogical composition of the mineral dust should be taken into account. Zhou et al. [2005] reported mean diurnal $\Delta \mathrm{F}^{\text {eff }}$ values lower than the obtained ones in the current study both for Arabian dust and for biomass burning.

[38] AERONET provides the solar fluxes, radiative forcing and forcing efficiency in whole solar spectrum $0.2-4.0 \mu \mathrm{m}$ (products available via AERONET website). Nevertheless through the comparison with ground-based measurements, only a small fraction of the solar broadband fluxes (from 0.2 to $\sim 0.3$ and from 2.8 to $4.0 \mu \mathrm{m}$ ) cannot be validated directly. The contribution of the ultraviolet 
C spectral interval (from 0.2 to $\sim 0.3 \mu \mathrm{m}$ ) can be ruled out, since this region is entirely absorbed by the atmospheric gases, and hence it has not any influence on validation tests. In the case of the infrared portion (from 2.8 to $4.0 \mu \mathrm{m}$ ), the solar energy at surface in this region constitutes a small fraction of broadband energy in total spectral range $(0.2-$ $4.0 \mu \mathrm{m})$ and it is expected that the errors in this range are in the same order or less than validated ones. Anyhow this portion represents only $\sim 1 \%$ of the total solar flux, and so its contribution as a bias should not be appreciable. Therefore the uncertainties derived in the observed spectral interval $(\sim 0.3$ to $2.8 \mu \mathrm{m})$ can be assumed as similar to absolute accuracy and valid for total AERONET spectral range $(0.2-4.0 \mu \mathrm{m})$.

\section{Conclusions}

[39] The SolRad-Net and BSRN solar networks provide an extensive database for validating the AERONET radiative products under a variety of aerosol regimes. Thus, in this paper, instantaneous AERONET solar broadband fluxes (F) at the bottom of the atmosphere have been compared with co-incident ground-based broadband solar radiation measurements. The uncertainties in the calculated aerosol radiative forcing $(\Delta F)$ and forcing efficiency $\left(\Delta F^{\text {eff }}\right)$ at surface were also estimated. The stations were selected as representative of different aerosol influences: background continental, biomass burning, desert dust, urban-industrial and maritime aerosols. Also, Mauna Loa Observatory was included in the study to account for situations with very low aerosol load.

[40] For the solar broadband fluxes and radiative forcing, the AERONET retrievals show convincing agreement with surface measurements. In global terms, a small overestimation of $9 \pm 12 \mathrm{Wm}^{-2}$ for measured radiation was found, within the uncertainty of BSRN and SolRad-Net observed data. The differences between AERONET modeled and measured, fluxes and $\Delta \mathrm{F}$, are within $\sim 15 \mathrm{Wm}^{-2}$ for all stations. Thus, by type of aerosols, the differences are situated in $\pm 8 \mathrm{Wm}^{-2}$ for background continental with a mean underestimation of $-3 \mathrm{Wm}^{-2}, \pm 10 \mathrm{Wm}^{-2}$ for urbanindustrial and $\pm 13 \mathrm{Wm}^{-2}$ biomass burning with an overestimation, on average, of $14 \mathrm{Wm}^{-2}$ and $6 \mathrm{Wm}^{-2}$, respectively. For desert dust and oceanic conditions the level of accuracy ranges from \pm 10 to $\pm 14 \mathrm{Wm}^{-2}$, whereas an overestimation less than $13 \mathrm{Wm}^{-2}$ was found for maritime aerosols and up to $16 \mathrm{Wm}^{-2}$ in the case of desert dust. Under clear atmosphere conditions a dispersion of $\pm 10 \mathrm{Wm}^{-2}$ was found. On contrary to solar fluxes and radiative forcing, where the aerosol load does not seem decisive on flux calculations by aerosol optical depth ranges, the highest dispersion for $\Delta \mathrm{F}^{\mathrm{eff}}$ estimates is found for clearest situations due to the modulation of the low aerosol load. In general, the uncertainties in the observed data due to instrumental effects and model restrictions as the retrieved surface albedo are assessed to be the most likely error sources.

[41] In order to evaluate the observed uncertainty of the $\Delta \mathrm{F}$, most of the calculations assume no errors in the values of solar fluxes without aerosols or that these are negligible regarding the observed uncertainty of measurements with aerosol presence [e.g., Bush and Valero, 2003]. Nevertheless, for Mauna Loa Observatory, which could be consider as representative of a clear atmosphere, the uncertainties are in the same range $\left(2 \pm 10 \mathrm{Wm}^{-2}\right)$ that those found with aerosols. So, it is necessary to put attention to this assumption because it seems to be not completely valid.

[42] Because of ground-based measurements only it is possible to validate these radiative magnitudes at surface, future studies will be conducted to complete this analysis, validating of the upwelling fluxes and aerosol radiative forcing at the TOA by means of using satellite observations, such as Cloud and the Earth's Radiant Energy System (CERES) measurements.

[43] Acknowledgments. We acknowledge the Ministry of Education and Science (MEC, Spain) for the next supports: projects CGL2004-05984C07-05, CGL2005-03428-C04-02, and CGL2007-66477-C02-02/CLI, and PI042005/033. We gratefully acknowledge the data provided by BSRN, SolRad-Net, MLO, and AERONET networks. Finally, we wish to express our appreciation to the operators of stations for their help on running the instruments.

\section{References}

Abel, S. J., E. J. Highwood, J. M. Haywood, and M. A. Stringer (2005), The direct radiative effect of biomass burning aerosols over southern Africa, Atmos. Chem. Phys. Discuss., 5, 1165-1211, AERONET's Version 2.0 quality assurance criteria, available at http://aeronet.gsfc.nasa.gov/.

Andreae, T. W., M. O. Andreae, C. Ichoku, W. Maenhaut, J. Cafmeyer, A. Karnieli, and L. Orlovsky (2002), Light scattering by dust and anthropogenic aerosol at a remote site in the Negev desert, Israel, J. Geophys. Res., 107(D2), 4008, doi:10.1029/2001JD900252.

Bush, B. C., and F. P. J. Valero (2003), Surface aerosol radiative forcing at Gosan during the ACE-Asia campaign, J. Geophys. Res., 108(D23), 8660, doi:10.1029/2002JD003233.

Cox, C., and W. Munk (1954), The measurements of the roughness of the sea surface from photographs of the sun's glitter, J. Opt. Soc. Am., 44, $838-850$

Derimian, Y., A. Karnieli, Y. J. Kaufman, M. O. Andreae, T. W. Andreae, O. Dubovik, W. Maenhaut, I. Koren, and B. N. Holben (2006), Dust and pollution aerosols over the Negev desert, Israel: Properties, transport, and radiative effect, J. Geophys. Res., 111, D05205, doi:10.1029/ 2005JD006549.

Derimian, Y., J. F. Leon, O. Dubovik, I. Chiapello, D. Tanré, A. Sinyuk, F. Auriol, T. Podvin, G. Brogniez, and B. N. Holben (2008), Radiative properties of aerosol mixture observed during the dry season 2006 over M'Bour, Senegal (AMMA campaign), J. Geophys. Res., 113, D00C09, doi:10.1029/2008JD009904.

Dubovik, O., and M. D. King (2000), A flexible inversion algorithm for retrieval of aerosol optical properties from sun and sky radiance measurements, J. Geophys. Res., 105, 20,673-20,696.

Dubovik, O., A. Smirnov, B. N. Holben, M. D. King, Y. J. Kaufman, T. F. Eck, and I. Slutsker (2000), Accuracy assessment of aerosol optical properties retrieval from AERONET sun and sky radiance measurements, J. Geophys. Res., 105, 9791-9806.

Dubovik, O., B. N. Holben, T. F. Eck, A. Smirnov, Y. J. Kaufman, M. D. King, D. Tanré, and I. Slutsker (2002a), Variability of absorption and optical properties of key aerosol types observed in worldwide locations, J. Atmos. Sci., 59, 590-608.

Dubovik, O., B. N. Holben, T. Lapyonok, A. Sinyuk, M. I. Mishchenko, P. Yang, and I. Slutsker (2002b), Non-spherical aerosol retrieval method employing light scattering by spheroids, Geophys. Res. Lett., 29(10), 1415, doi:10.1029/2001GL014506.

Dubovik, O., et al. (2006), Application of light scattering by spheroids for accounting for particle non-sphericity in remote sensing of desert dust, J. Geophys. Res., 111, D11208, doi:10.1029/2005JD006619.

Dubuisson, P., J. C. Buriez, and Y. Fouquart (1996), High spectral resolution solar radiative transfer in absorbing and scattering media, application to the satellite simulation, J. Quant. Spectrosc. Radiat. Transfer, 55(1), $103-126$.

Dubuisson, P., D. Dessailly, M. Vesperini, and R. Frouin (2004), Water vapor retrieval over ocean using near-IR imagery, J. Geophys. Res., 109, D19106, doi:10.1029/2004JD004516. 
Dutton, E. G., and B. A. Bodhaine (2001), Solar irradiance anomalies caused by clear-sky transmission variations above Mauna Loa 1957 1999, J. Clim., 14, 3255-3262.

Dutton, E. G., J. J. Michalsky, T. Stoffel, B. W. Forgan, J. Hickey, D. W. Nelson, T. L. Alberta, and I. Reda (2001), Measurement of broadband diffuse solar irradiance using current commercial instrumentation with a correction for thermal offset errors, J. Atmos. Oceanic Technol., 18, $297-314$

Eck, T. F., B. N. Holben, J. S. Reid, O. Dubovik, A. Smirnov, N. T. O’Neill, I. Slutsker, and S. Kinne (1999), Wavelength dependence of the optical depth of biomass burning, urban, and desert dust aerosols, J. Geophys. Res., 104, 31,333-31,349.

Eck, T. F., et al. (2008), Spatial and temporal variability of column-integrated aerosol optical properties in the southern Arabian Gulf and United Arab Emirates in summer, J. Geophys. Res., 113, D01204, doi:10.1029/ 2007JD008944.

Formenti, P., et al. (2001), Aerosol optical properties and large-scale transport of air masses: Observations at a coastal and a semiarid site in the eastern Mediterranean during summer 1998, J. Geophys. Res., 106, 9807-9826.

Ganor, E. (1994), The frequency of Saharan dust episodes over Tel Aviv, Israel, Atmos. Environ., 28, 2867-2871.

García, O. E., A. M. Díaz, F. J. Expósito, J. P. Díaz, J. Gröbner, and V. E. Fioletov (2006), Cloudless aerosol forcing efficiency in the UV region from AERONET and WOUDC databases, Geophys. Res. Lett., 33 , L23803, doi:10.1029/2006GL026794.

García, O. E., A. M. Díaz, F. J. Expósito, J. P. Díaz, M. D. Gelado, and C. Guirado (2008), A methodology to evaluate the aerosol effective radius based on MODIS aerosol products applicable to other satellite platforms, Int. J. Remote Sens., in press.

Gerasopoulos, E., M. O. Andreae, C. S. Zerefos, T. W. Andreae, D. Balis, P. Formenti, P. Merlet, V. Amiridis, and C. Papastefanou (2003), Climatological aspects of aerosol optical properties in Northern Greece, Atmos. Chem. Phys., 3, 2025-2041.

Hall, D. K., G. A. Riggs, and V. V. Salomonson (2002), MODIS/Terra Snow Cover Daily L3 Global 0.05Deg CMG V004, February 2000 to Present. Boulder, CO, USA: National Snow and Ice Data Center. Digital media, 2002 updated daily.

Hatzianastassiou, N., C. Matsoukas, A. Fotiadi, K. G. Pavlakis, E. Drakakis, D. Hatzidimitriou, and I. Vardavas (2005), Global distribution of Earth's surface shortwave radiation budget, Atmos. Chem. Phys., 5, 2847-2867.

Holben, B. N., et al. (1998), AERONET-A federated instrument network and data archive for aerosol characterization, Remote Sens. Environ., 66 , $1-16$.

Holben, B. N., et al. (2001), An emerging ground-based aerosol climatology: Aerosol optical depth from AERONET, J. Geophys. Res., 106 , $12,067-12,097$

Husar, R. B., et al. (2001), Asian dust events of April 1998, J. Geophys Res., 106, 18,317-18,330.

Intergovernmental Panel on Climate Change (2001), The Scientific Basis (2001), Cambridge Univ. Press, New York.

Intergovernmental Panel on Climate Change (2007), The Physical Science Basis, Fourth Assessment Report Summary (2007), Cambridge Univ. Press, New York.

Israelevich, P. L., E. Ganor, Z. Levin, and J. H. Joseph (2003), Annual variations of physical properties of desert dust over Israel, J. Geophys. Res., 108(D13), 4381, doi:10.1029/2002JD003163.

Kaskaoutis, D. G., H. D. Kambezidis, N. Hatzianastassiou, P. G Kosmopoulos, and K. V. S. Badarinath (2007), Aerosol climatology: On the discrimination of aerosol types over four AERONET sites, Atmos. Chem. Phys. Discuss., 7, 6357-6411.

Kato, S., T. P. Ackerman, E. G. Dutton, N. Laulainen, and N. Larson (1999), A comparison of modeled and measured surface shortwave irradiance for a molecular atmosphere, J. Quant. Spectrosc. Radiat. Transfer, $61,493-502$

Kubilay, N., T. Cokacar, and T. Oguz (2003), Optical properties of mineral dust outbreaks over the northeastern Mediterranean, J. Geophys. Res. 108(D21), 4666, doi:10.1029/2003JD003798.

Lacis, A. A., and V. Oinas (1991), A description of the correlated kdistribution method for modeling nongray gaseous absorption, thermal emission, and multiple scattering in vertically inhomogeneous atmospheres, J. Geophys. Res., 96, 9027-9063.

Long, C. N., and T. P. Ackerman (2000), Identification of clear skies from broadband pyranometer measurements and calculation of downwelling shortwave cloud effects, J. Geophys. Res., 105, 15,609-15,626.

Lucht, W., and J. L. Roujean (2000), Consideration in parametric modeling of BRDF and albedo from multi-angular satellite sensors observations, Remote Sens. Rev., 18, 343-379.
McArthur, L. J. B., D. H. Halliwell, O. J. Niebergall, N. T. O’Neill, J. R. Slusser, and C. Wehrli (2003), Field comparison of network Sun photometers, J. Geophys. Res., 108(D19), 4596, doi:10.1029/2002JD002964.

Michalsky, J., E. Dutton, M. Rubes, D. Nelson, T. Stoffel, M. Wesley, M. Splitt, and J. DeLuisi (1999), Optimal measurements of surface shortwave irradiance using current instrumentation, J. Atmos. Oceanic Technol., 16, 55-69.

Mishchenko, M. I., L. D. Travis, R. A. Kahn, and R. A. West (1997), Modeling phase functions for dustlike tropospheric aerosols using a shape mixture of randomly oriented polydisperse spheroids, J. Geophys. Res., $102,16,831-16,847$.

Moody, E. G., M. D. King, S. Platnik, C. B. Schaaf, and F. Gao (2005), Spatially complete global spectral surface albedos: Value-added datasets derived from terra MODIS land products, IEEE Trans. Geosci. Remote Sens., 43, 144-158.

Myhre, G., T. K. Berntsen, J. M. Haywood, J. K. Sundet, B. N. Holben, M. Johnsrud, and F. Stordal (2003), Modeling the solar radiative impact of aerosols from biomass burning during the Southern African Regional Science Initiative (SAFARI-2000) experiment, J. Geophys. Res., 108(D13), 8501, doi:10.1029/2002JD002313.

Nakajima, T., and M. Tanaka (1988), Algorithms for radiative intensity calculations in moderately thick atmospheres using a truncation approximation, J. Quant. Spectrosc. Radiat. Transfer, 40, 51-69.

Nolin, A., R. L. Armstrong, and J. Maslanik (1998), Near Real-Time SSM/I EASE-Grid Daily Global Ice Concentration and Snow Extent, January 1998 to Present. Boulder, CO, USA: National Snow and Ice Data Center Digital media, 1998 update daily.

Ohmura, A., et al. (1998), Baseline Surface Radiation Network (BSRN/ WCRP): New precision radiometry for climate research, Bull. Am. Meteorol. Soc., 79, 2115-2136.

Remer, L. A., et al. (2005), The MODIS aerosol algorithm, products and validation, J. Atmos. Sci., 62, 947-973.

Roger, J. C., M. Mallet, P. Dubuisson, H. Cachier, E. Vermote, O. Dubovik, and S. Despiau (2006), A synergetic approach for estimating the local direct aerosol forcing: Application to an urban zone during the ESCOMPTE experiment, J. Geophys. Res., 111, D13208, doi:10.1029/2005JD006361. Russak, V., A. Kallisa, A. Jõeveerb, H. Ohvril, and H. Teralc (2007), Changes in the spectral aerosol optical thickness in Estonia (19512004), Proc. Est. Acad. Sci., Biol., Ecol., 56(1), 69-76.

Sato, M., J. Hansen, D. Koch, A. Lacis, R. Ruedy, O. Dubovik, B. Holben, M. Chin, and T. Novakovet (2003), Global atmospheric black carbon inferred from AERONET, Proc. Natl. Acad. Sci. U. S. A., 100, 63196324.

Schafer, J. S., B. N. Holben, T. F. Eck, M. A. Yamasoe, and P. Artaxo (2002a), Atmospheric effects on insolation in the Brazilian Amazon: Observed modification of solar radiation by clouds and smoke and derived single scattering albedo of fire aerosols, J. Geophys. Res., 107(D20), 8074, doi:10.1029/2001JD000428.

Schafer, J. S., T. F. Eck, B. N. Holben, P. Artaxo, M. A. Yamasoe, and A. S Procopio (2002b), Observed reductions of total solar irradiance by biomass-burning aerosols in the Brazilian Amazon and Zambian Savanna, Geophys. Res. Lett., 29(17), 1823, doi:10.1029/2001GL014309.

Schafer, J. S., T. F. Eck, B. N. Holben, P. Artaxo, and A. F. Duarte (2008), Characterization of the optical properties of atmospheric aerosols in Amazônia from long-term AERONET monitoring (1993-1995 and 19992006), J. Geophys. Res., 113, D04204, doi:10.1029/2007JD009319.

Sinyuk, A., et al. (2007), Simultaneous retrieval of aerosol and surface properties from a combination of AERONET and satellite data, Remote Sens. Environ., 107, 90-108.

Smirnov, A. V., O. Dubovik, N. T. O’Neill, L. A. Remer, T. F. Eck, I. Slutsker, and D. Savoie (2000a), Measurement of atmospheric optical parameters on U.S. Atlantic coast sites, ships and Bermuda during TARFOX, J. Geophys. Res., 105, 9887-9901.

Smirnov, A., B. N. Holben, T. F. Eck, O. Dubovik, and I. Slutsker (2000b), Cloud screening and quality control algorithms for the AERONET database, Remote Sens. Environ., 73, 337-349.

Smirnov, A., B. N. Holben, Y. J. Kaufman, O. Dubovik, T. F. Eck, I. Slutsker, C. Pietras, and R. N. Halthore (2002), Optical properties of atmospheric aerosol in maritime environments, J. Atmos. Sci., 59, 501-523.

Smirnov, A., B. N Holben, A. Lyapustin, I. Slutsker, and T. F. Eck (2004), AERONET processing algorithms refinement, AERONET Workshop, May 10-14, 2004, El Arenosillo, Spain.

Stamnes, K., S. C. Tsay, W. Wiscombe, and K. Jayaweera (1988), Numerically stable algorithm for discrete-ordinate-method radiative transfer in multiple scattering and emitting layered media, Appl. Opt., 27, 25022509.

Thulasiraman, S., N. T. O’Neill, A. Royer, B. N. Holben, D. L. Westphal, and L. J. B. McArthur (2002), Sunphotometric observations of the 2001 
Asian dust storm over Canada and the U.S., Geophys. Res. Lett., 29(8), 1255, doi:10.1029/2001GL014188.

Xia, X., H. Chen, Z. Li, P. Wang, and J. Wang (2007), Significant reduction of surface solar irradiance induced by aerosols in a suburban region in northeastern China, J. Geophys. Res., 112, D22S02, doi:10.1029 2006JD007562.

Zhou, M., H. Yu, R. E. Dickinson, O. Dubovik, and B. N. Holben (2005), A normalized description of the direct effect of key aerosol types on solar radiation as estimated from aerosol robotic network aerosols and moderate resolution imaging spectroradiometer albedos, J. Geophys. Res., 110, D19202, doi:10.1029/2005JD005909.

Y. Derimian, O. Dubovik, and P. Dubuisson, Laboratoire d'Optique Amosphérique (UMR 8518), Bâtiment P5-Bureau 333, Université des Sciences et Technologies de Lille I, Villeneuve d'Ascq, Cedex 59655, France.

A. M. Díaz, J. P. Díaz, F. J. Expósito, and O. E. García, Grupo de Observación de la Tierra y la Atmósfera-GOTA, Departamento de Física
F.E.E.S., Universidad de La Laguna, Avda. Astrofísico Francisco Sánchez s/n La Laguna 38200, Tenerife, Spain. (ogarcia@ull.es)

E. G. Dutton, NOAA Climate Monitoring and Diagnostics Laboratory, 325 Broadway, Boulder, CO 80305-3337, USA.

T. F. Eck and A. Sinyuk, Laboratory for Terrestrial Physics Code 614.4 NASA Goddard Spaceflight Center, 8600 Greenbelt Road, Greenbelt, MD 20771, USA.

C. A. García, Departamento de Estadística e Investigación Operativa, Universidad de La Laguna, Avda. Astrofísico Francisco Sánchez s/n La Laguna, Tenerife 38200, Spain.

B. N. Holben, Biospheric Sciences Branch Code 614.4, NASA Goddard Space Flight Center, 8600 Greenbelt Road, Greenbelt, MD 20771, USA.

J.-C. Roger, Laboratoire de Météorologie Physique/OPGC, Université Blaise Pascal (Clermont-Ferrand 2)-CNRS, Campus des Cézeaux, Bâtiment 5, 24 avenue des Landais, 63177 Aubières, Cedex, France.

J. S. Schafer, Biospheric Sciences Branch Code 614.4, NASA Goddard Space Flight Center, 8600 Greenbelt Road, Greenbelt, MD 20771, USA. 